\title{
Aeroacoustic Evaluation of Flap and Landing Gear Noise Reduction Concepts
}

\author{
Mehdi R. Khorrami, ${ }^{*}$ William M. Humphreys, Jr., ${ }^{\dagger}$ and David P. Lockard ${ }^{\ddagger}$ \\ NASA Langley Research Center, Hampton, Virginia, 23681 \\ and \\ Patricio A. Ravetta ${ }^{\S}$ \\ AVEC Inc., Blacksburg, Virginia, 24060
}

\begin{abstract}
Aeroacoustic measurements for a semi-span, $18 \%$ scale, high-fidelity Gulfstream aircraft model are presented. The model was used as a test bed to conduct detailed studies of flap and main landing gear noise sources and to determine the effectiveness of numerous noise mitigation concepts. Using a traversing microphone array in the flyover direction, an extensive set of acoustic data was obtained in the NASA Langley Research Center 14- by 22-Foot Subsonic Tunnel with the facility in the acoustically treated openwall (jet) mode. Most of the information was acquired with the model in a landing configuration with the flap deflected $39^{\circ}$ and the main landing gear alternately installed and removed. Data were obtained at Mach numbers of $0.16,0.20$, and 0.24 over directivity angles between $56^{\circ}$ and $116^{\circ}$, with $90^{\circ}$ representing the overhead direction. Measured acoustic spectra showed that several of the tested flap noise reduction concepts decrease the sound pressure levels by $2-4 \mathrm{~dB}$ over the entire frequency range at all directivity angles. Slightly lower levels of noise reduction from the main landing gear were obtained through the simultaneous application of various gear devices. Measured aerodynamic forces indicated that the tested gear/flap noise abatement technologies have a negligible impact on the aerodynamic performance of the aircraft model.
\end{abstract}

\section{Introduction}

Reducing the adverse environmental impact of aircraft noise emissions on population centers adjacent to major airports is an important goal of NASA. Airframe noise is a significant component of aircraft noise during approach to landing when the undercarriage and wing high-lift system are deployed. Prior aeroacoustic studies (flight tests and model scale experiments) have identified the aircraft landing gear and high-lift devices such as slats and flaps to be the most prominent airframe noise sources. ${ }^{1-10}$ NASA's Environmentally Responsible Aviation (ERA) project is vigorously pursuing the advancement and maturation of airframe noise reduction concepts that will minimize aircraft noise footprints on the ground while maintaining aerodynamic efficiency.

The present work is part of a larger airframe noise study being executed under a NASA-Gulfstream partnership. The joint study is a multi-pronged, multi-faceted effort comprised of: a) high-fidelity, large-scale computations for the advancement of simulation-based noise prediction tools, b) a series of model-scale wind tunnel tests targeting the development and evaluation of airframe noise mitigation technologies as well as the acquisition of an extensive aeroacoustic database for validation of advanced noise prediction capabilities, and c) full-scale flight tests to determine the geometric fidelity, installation, and Reynolds number effects on airframe noise sources, and ultimately to evaluate the effectiveness of the best performing noise reduction concepts in a relevant environment. The NASAGulfstream joint effort began with an acoustic flight test in 2006 where the prominent airframe noise sources associated with a Gulfstream aircraft were identified and documented. ${ }^{10}$ The major noise sources are the flap sideedges, main landing gear, and nose landing gear. The tested aircraft high-lift system does not have wing leading edge slats. Gear-flap flow interaction was also identified as a potential source of noise.

For the wind tunnel tests, a high-fidelity and highly-instrumented 18\% scale, semi-span model of the Gulfstream aircraft deployed during the 2006 flight test was designed and fabricated at the NASA Langley Research Center (LaRC). The model was produced specifically to conduct airframe noise studies and evaluate advanced noise

\footnotetext{
* Aerospace Engineer, Computational AeroSciences Branch, Associate Fellow AIAA

${ }^{\dagger}$ Assistant Branch Head, Advanced Sensing and Optical Measurement Branch, Senior Member AIAA

‡ Aerospace Engineer, Computational AeroSciences Branch, Senior Member AIAA

${ }^{\S}$ Chief Research Engineer, Senior Member AIAA
} 
mitigation concepts for reducing main landing gear, flap, and gear-flap interaction noise. Aeroacoustic testing was executed in multiple stages through three entries in the NASA LaRC 14- by 22-Foot Subsonic Tunnel (14 x 22). The initial entry, lasting four weeks, was completed in November of 2010. This test was devoted to documenting the aerodynamic characteristics of the model. Global forces (lift and drag) along with steady and unsteady surface pressure measurements were acquired. Detailed accounts of model development and aerodynamic results obtained during the 2010 test are given in Refs. 11 and 12. The second 14 x 22 tunnel entry, lasting five weeks, was concluded in late March of 2013. This segment was dedicated to comprehensive aeroacoustic testing of the model in a landing configuration with and without flap/gear noise reduction devices applied. During this entry, aerodynamic and acoustic measurements were performed simultaneously. To reduce the impact of background noise and improve the quality of the collected acoustic data, the $14 \times 22$ tunnel was operated in an open-wall (open-jet test section with floor) acoustic configuration whereby the test section floor, raised ceiling, and side walls were treated with sound absorbing foam wedges. The acoustic measurements were obtained using a traversing microphone array in the flyover direction. The third entry, lasting four weeks, was completed in late April of 2013. Employing particle image velocimetry (PIV) and laser velocimetry (LV) techniques, this final entry was dedicated to acquiring offsurface flow measurements from the $18 \%$ scale model baseline landing configuration with emphasis on gear-flap flow interaction.

This paper is focused mainly on the acoustic measurements obtained during the second wind tunnel entry. We present sample comparisons of power spectral density levels for configurations without and with noise reduction concepts applied to the flap and main landing gear. Details of the aerodynamic data measured concurrently during the second entry and off-surface PIV measurements acquired during the third entry, are given in companion papers by Neuhart et al. ${ }^{13}$ and Yao et al. ${ }^{14}$ respectively.

\section{Test Setup}

Major components of the test apparatus are introduced in this section. Brief descriptions of hardware elements such as aircraft model, noise reduction concepts, $14 \times 22$ wind tunnel, and microphone phased array are provided. Also included are salient details of the software used for data reduction and analysis.

\section{A. Aircraft Model}

The test bed was an $18 \%$ scale, semi-span, high-fidelity replica of a Gulfstream aircraft (see Fig. 1). It was designed, fabricated, instrumented, and integrated at NASA LaRC based on a set of geometry files provided by Gulfstream. The model comprises a fuselage, wing, flap, flow-through nacelle, pylon, and main landing gear. From nose to tail, the model is 185.4 in $(4.709 \mathrm{~m})$ long. The wing span (measured from the wind tunnel floor to the tip of the winglet) is 104.5 in $(2.654 \mathrm{~m})$. Details on the model development effort, including its fabrication, instrumentation, and integration are given in Refs. 11 and 12.

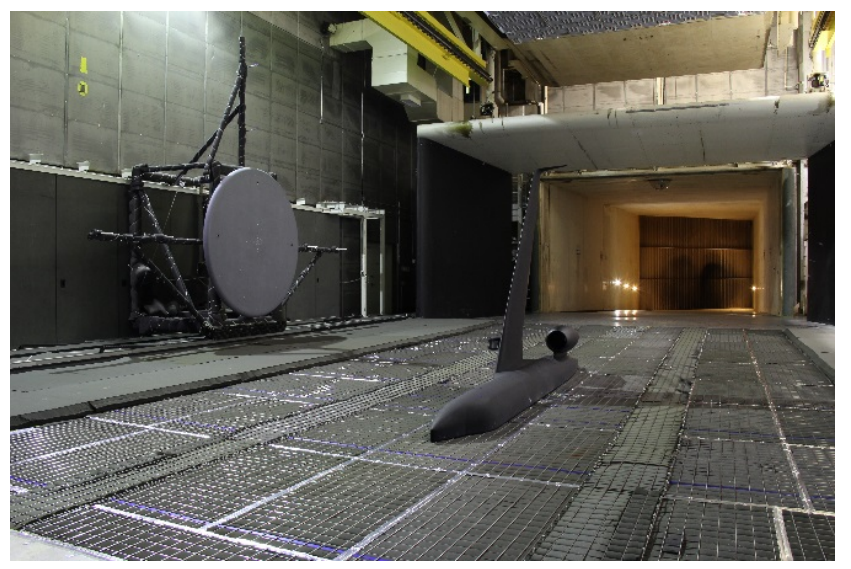

a) Installed in NASA LaRC 14 x 22 tunnel.

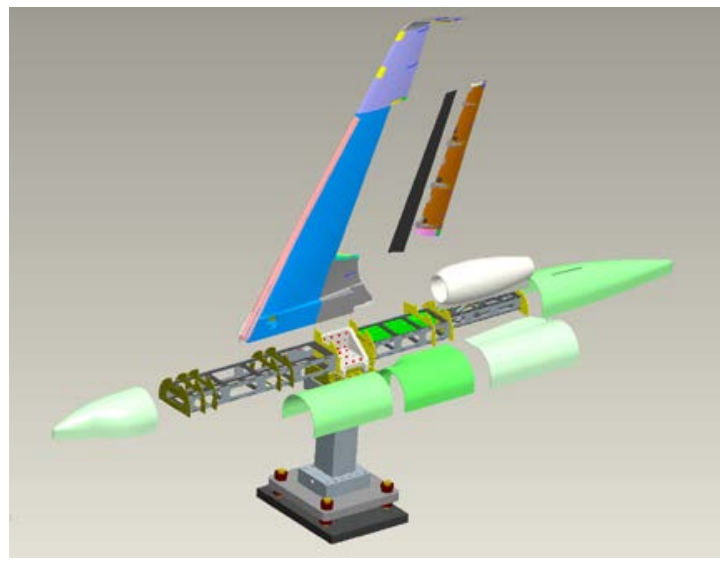

b) Exploded view.

Figure 1. 18\% scale semi-span Gulfstream aircraft model. 


\section{B. Noise Reduction Hardware}

\section{Flap}

As described in Ref. 11, the model flap was designed in a modular fashion, with removable inboard and outboard tips to facilitate testing of numerous noise reduction concepts. For the 2013 acoustic tests, six independent concepts were designed and over thirty permutations of these concepts were fabricated and evaluated. Figure 2 displays the flap noise reduction hardware that was produced. Most of the concepts tested can be separated into five broad categories: a) porous skin treatment, b) bulk and locally reactive acoustic liners, c) Flap Edge Noise Reduction Fins (FENoRFins) with both circular and non-circular fin cross sections, d) FLEXible Side-Edge Link (FLEXSEL), and e) Reactive Orthotropic Lattice Diffuser (ROLD). Common among the various concepts is the extent of the tip area receiving treatment, which was carefully tailored to remain very small relative to the total flap surface area. For all the concepts tested, the spanwise extent of treated area scaled with local maximum flap thickness, $t_{\max }$, at either (inboard or outboard) tip and typically remained less than $1.5 t_{\max }$. To maintain the overall aerodynamic efficiency of the flap, the first $10 \%$ of the flap chord at the leading edge was excluded from any treatment or other geometrical alterations. A brief description of each concept is provided in the following sections.

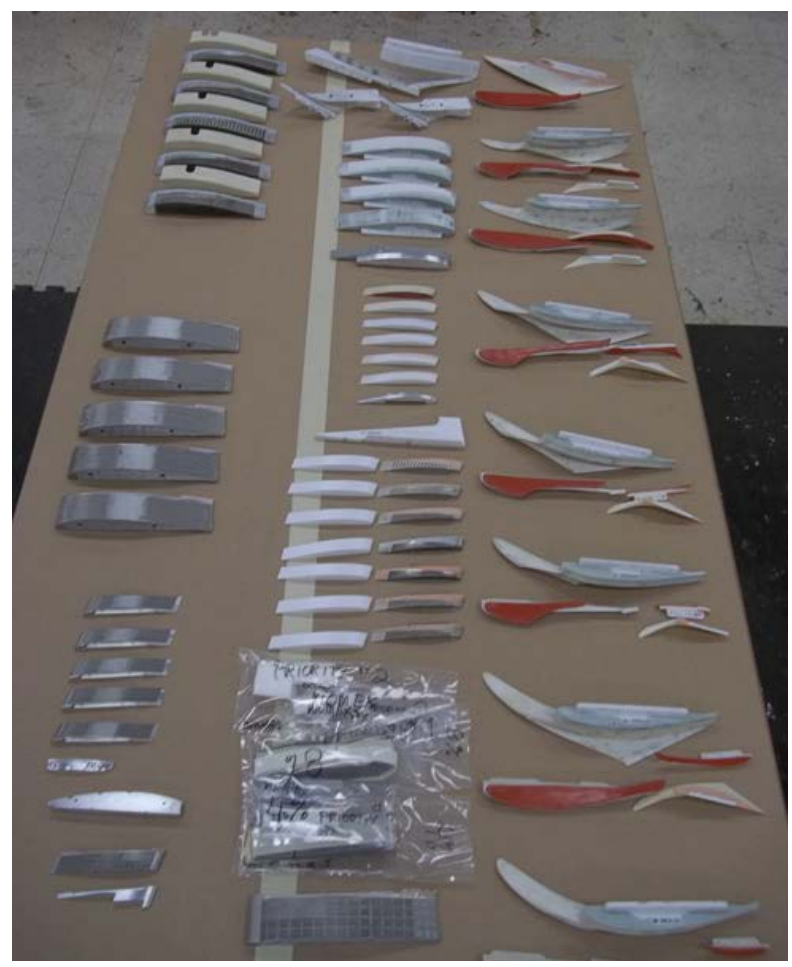

Figure 2. Flap noise reduction hardware.

\section{a. Porous surface treatment}

Based on previous studies ${ }^{8}$ and computational simulations ${ }^{15}$ to guide the design, the extent of the treated area for the porous surface treatment concept was tailored to minimize aerodynamic performance penalties while achieving substantial noise reduction. Cage-like structures having the local flap profile at each tip (see Fig. 3a) were produced with the exterior surfaces of the cage ribs recessed $0.008 \mathrm{in}(0.2 \mathrm{~mm})$ to accommodate a wire mesh skin. The skin was carefully spot-welded to the cage (see Fig. 3b) to avoid wrinkles and other surface imperfections. The resulting treated area formed a surface that was continuous with the rest of the flap surfaces. For the present evaluation, four sets (a set refers to both inboard and outboard tips) were fabricated. Porous skin surface resistances were 150, 270, 450, and 570 Rayl. To determine concept performance dependencies on the size of the treated area, a fifth set of tips was produced whereby the spanwise extent of the treatment was reduced by $33 \%$ on both top and bottom flap surfaces. For this variation, the 270 Rayl wire mesh skin was used to cover the affected surface segments. 


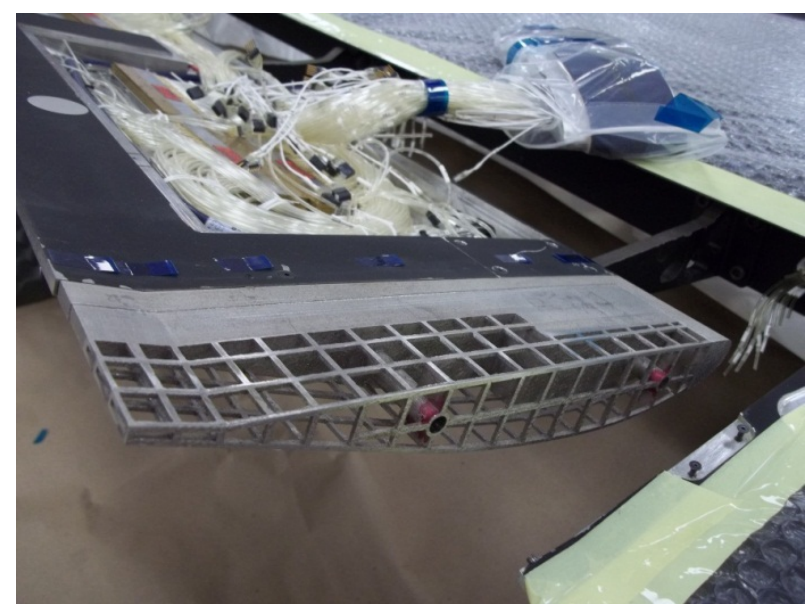

a) Cage-like structure

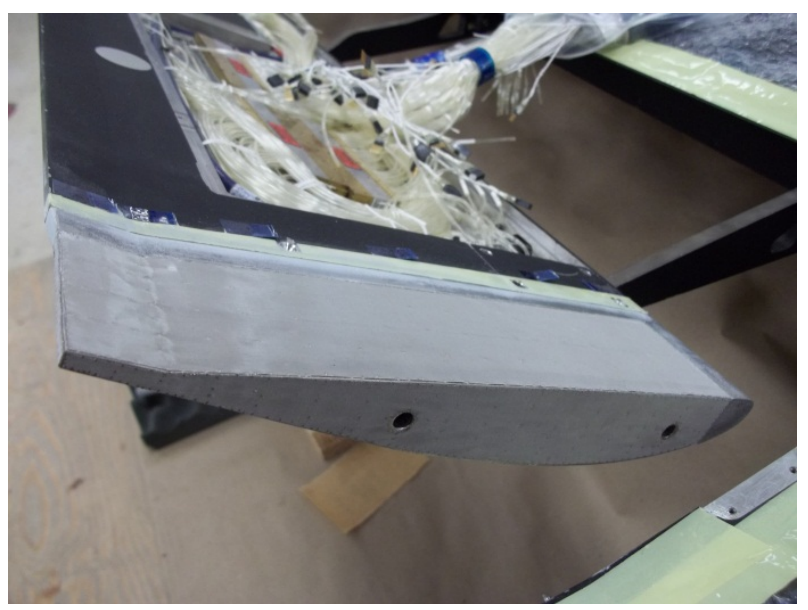

b) porous surface tip

Figure 3. Porous tip treatment concept.

\section{b. Acoustic liners}

Two distinct designs using bulk and locally reactive liners were fabricated. To accommodate the former, a sixth set of porous tips (see previous section) with a slightly modified design was produced. These tips, having an extremely low resistive skin (20 Rayl mesh), were used to test bulk absorbent materials filling the interior volume of the cages (see Figs. 4a and 4b). The materials tested were Nomex Felt Model 4485R; and FeCrAlY, 80 points per inch, with $8 \%$ and $4 \%$ density metal foams.

The locally reactive acoustic liner design comprised a series of serpentine channels of various lengths that terminated within the interior volume adjacent to the flap tips (Fig. 4c). The design (developed by liner experts at NASA LaRC) incorporated a select combination of these channels to achieve optimal absorption over a wide range of frequencies. This liner concept can be improved further to ensure near-uniform absorption over the frequency range of interest. The model flap interior volume available near the tips was not sufficient to house an appropriate number of chambers, preventing us from obtaining the most efficient design. Therefore, the results obtained with the current design must be viewed as proof-of-concept, requiring further optimization to achieve its maximum noise absorption potential.

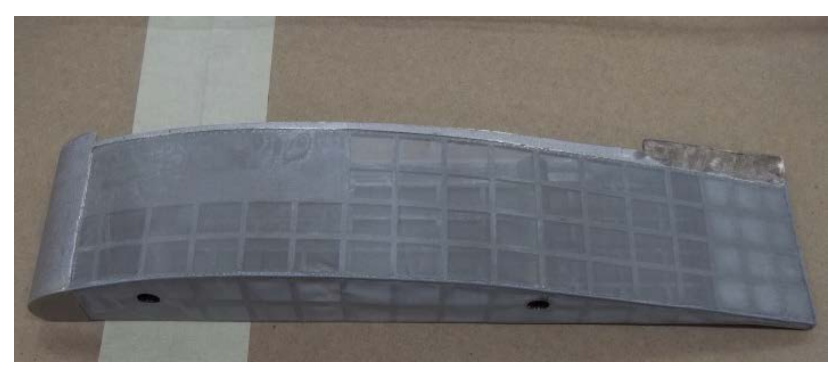

a) Empty 20-Rayl skin tip

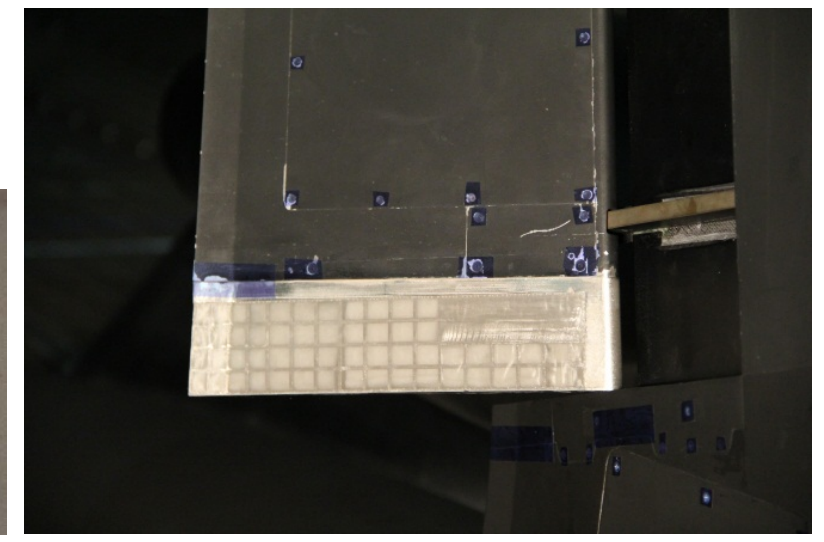

b) 20-Rayl skin tip filled with Nomex material

Figure 4. Liner concepts. 


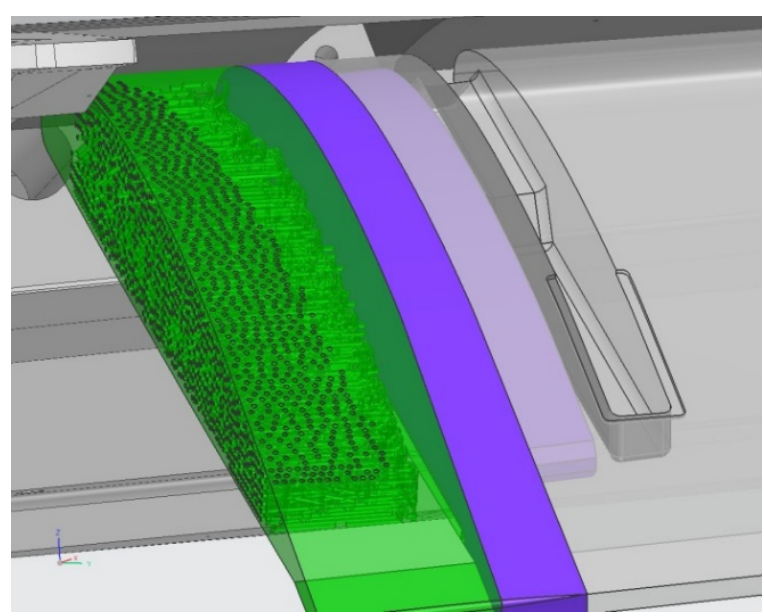

c) Locally reactive liner with serpentine passages

Figure 4. Concluded.

\section{c. Flap Edge Noise Reduction Fins (FENoRFins)}

Although somewhat different, concepts with circular and non-circular cross-section fins have been lumped under the common name Flap Edge Noise Reduction Fins (FENoRFins). As shown in Fig.5, all three surfaces at the flap tips are affected under this design. To preserve the aerodynamic efficiency of the flap, the regions adjacent to the leading and trailing edges were not treated. The spanwise extent of the fin region (i.e., fin length) followed a slanted pattern with the shortest fins applied near the leading edge and the longest fins placed towards the trailing edge of the flap. For the present test, non-circular cross-section FENoRFins of two widths (see Fig. 5a), termed "large" and "small", were fabricated. Circular cross-section fins of three different diameters (the spacing between centers of adjacent fins, non-dimensionalized by diameter, was maintained), referred to as "large", "medium", and "small" were fabricated and evaluated.

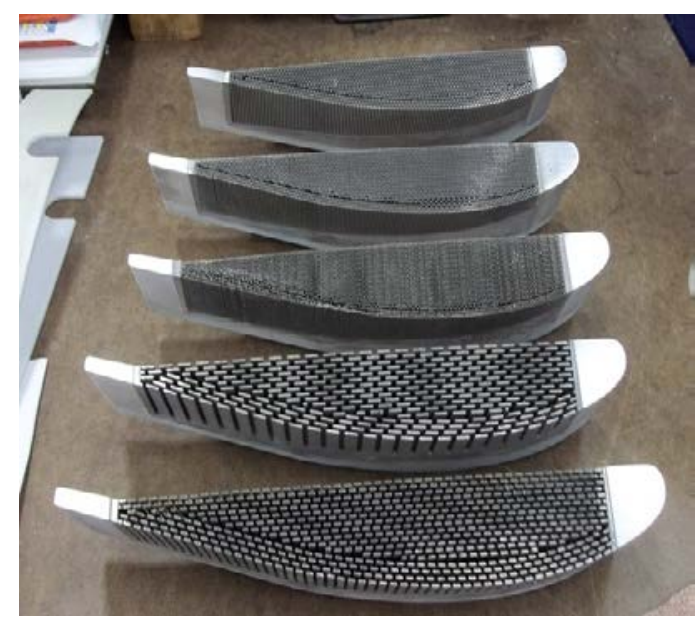

a) Circular and non-circular cross-section fins

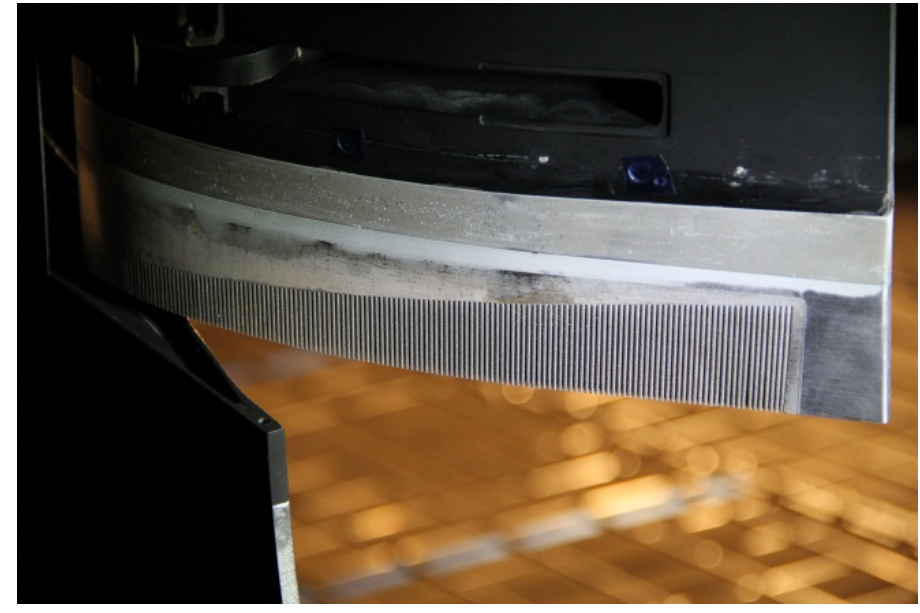

b) Medium diameter circular fins at flap inboard edge

Figure 5. FENoRFins concept.

\section{d. FLEXible Side-Edge Link (FLEXSEL)}

One of the flap concepts that were tested extensively is the FLEXible Side Edge Link (FLEXSEL). This structural-link design uses stretchable (hyper-elastic) materials for linking the flap side edge to the wing edge adjacent to the flap. Unlike the Continuous Mold Link (CML) concept, ${ }^{16-18}$ the transition/linkage occurs rather rapidly over a very short distance (less than $2 \%$ of the flap span) without the need to produce lift by the linkage surface. For the purpose of evaluating its noise reduction capability, both rigid (polycarbonate) and elastomeric 
(soft) versions of the FLEXSEL design were produced. Figure 6 shows the fabricated FLEXSEL concept as applied to the inboard and outboard flap tips of the $18 \%$ scale Gulfstream aircraft model. To determine the effect of spanwise extent on the performance of the concept, an additional set of rigid FLEXSEL tips with a $40 \%$ larger transition section was fabricated.

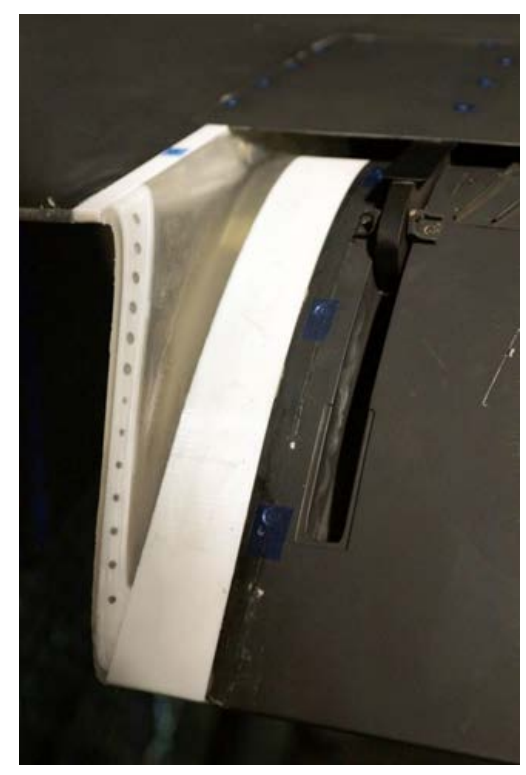

a) Inboard tip

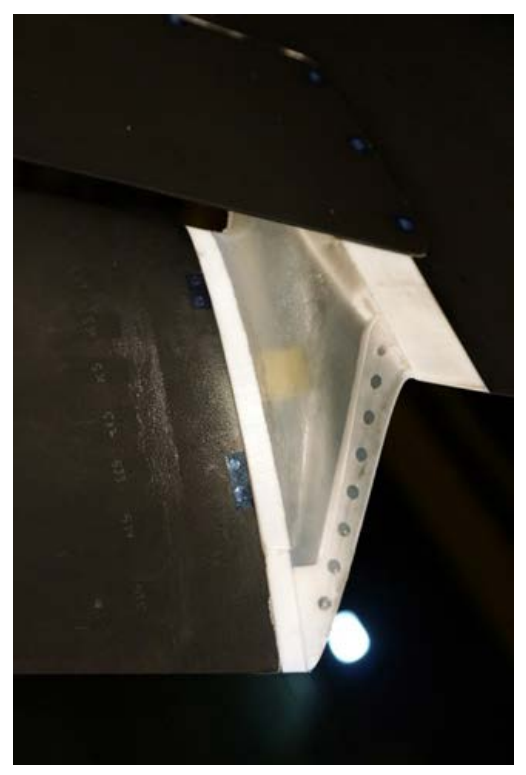

b) Outboard tip

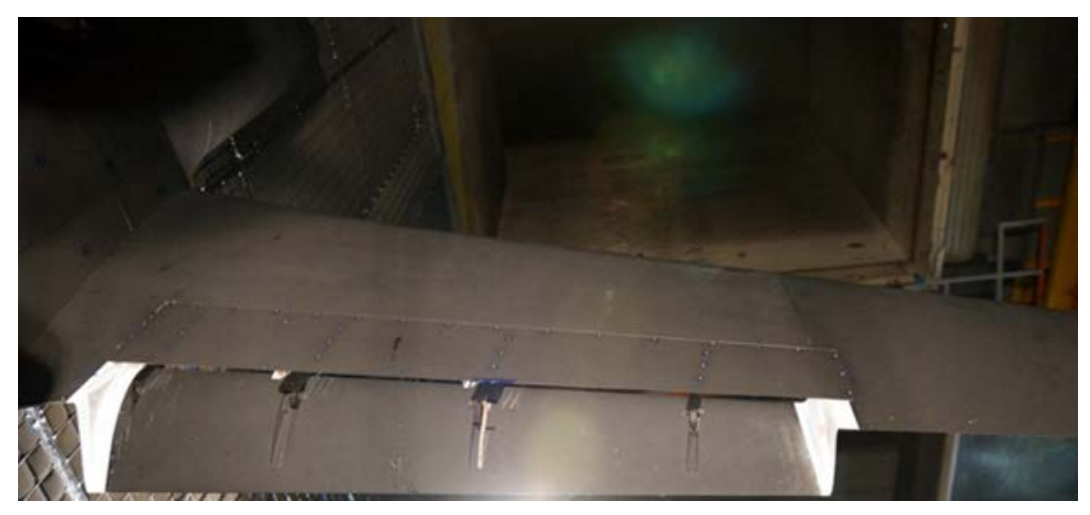

c) Top view of entire flap

Figure 6. FLEXSEL concept as installed on $18 \%$ scale Gulfstream aircraft model flap.

\section{e. Reactive Orthotropic Lattice Diffuser (ROLD)}

The Reactive Orthotropic Lattice Diffuser (ROLD) is a unique design that combines attributes of the porous skin treatment and liner concepts. For ROLD, all three surfaces in the flap tip region are porous. The internal structure of the design is comprised of passages or perforations that are orthogonally aligned in all three directions (see Fig. 7). Passages from each direction intersect, thereby creating a three dimensional lattice structure that is orthotropic in nature. For the present test campaign, three sets of ROLD tips with different perforation or hole sizes (while maintaining the same spacing between holes) were produced. These are referred to as "large holes", "medium holes", and "small holes" ROLD. 


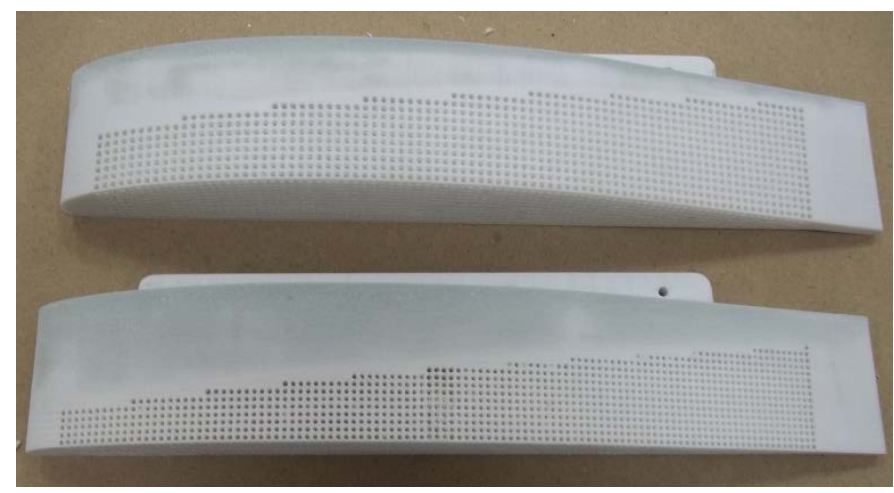

a) Medium and large diameter ROLD

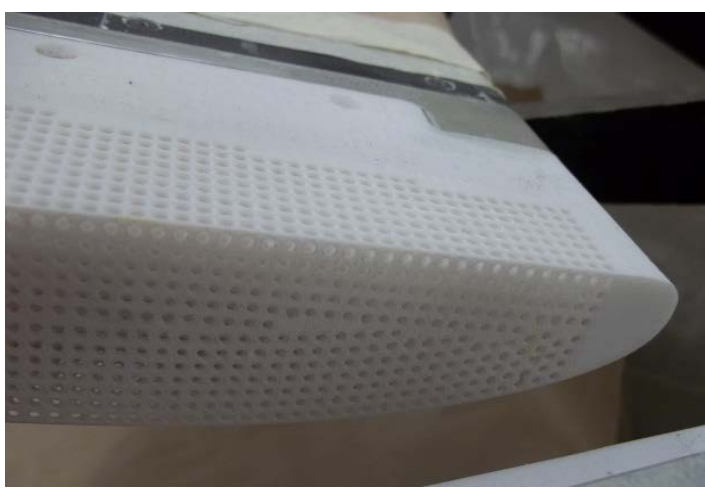

b) Installed at inboard tip

Figure 7. ROLD concept

\section{Main Landing Gear}

An aircraft undercarriage is a complex system comprising bluff body subcomponents of various shapes and sizes. Accordingly, no single concept could be expected to produce the desired noise reduction levels. Gear noise reduction must be approached with multiple, complementary concepts tailored to specific noise sources associated with individual subcomponents. Ideation and conceptual design of various landing gear fairings was accomplished under a collaborative effort among NASA, Goodrich Landing Gear Services, Exa Corporation, and Gulfstream. During the subsequent developmental phase conducted by Goodrich, high-fidelity computer simulations were used to obtain a set of viable fairing designs. The same computational approach was used to further refine some of the concepts to achieve designs that provided at least the minimum noise reduction goals for the gear component set by the group.

To evaluate the acoustic performance of the landing gear noise reduction concepts, a duplicate of the main landing gear of the $18 \%$ scale semi-span model was produced under a separate partnership between NASA and Goodrich Landing Gear Services. For identification purposes, the two main gear models will be referred to as the original gear and the Goodrich gear. A frontal view of the Goodrich main landing gear (baseline) is shown in Fig. 8. During two separate entries in the Virginia Tech Stability Tunnel (in its anechoic configuration), conducted during September of 2011 and July of 2012, the Goodrich gear was used as a standalone component to determine the effectiveness of numerous permutations of seven independent noise reduction concepts. The unpublished computational and experimental results from these studies were instrumental in identifying the most efficient technologies to be evaluated further on the $18 \%$ scale aircraft model in the $14 \times 22$ tunnel. These best performers are described below.

To reduce turbulent flow fluctuations in the upper segment of the gear, several small fairings, collectively called "upper fairings" and highlighted in Fig. 9a, were designed and evaluated. A main gear concept that proved to be very effective (and was tested extensively later during the 14 x 222013 entry) is the porous knee fairing design shown in Fig. 9b. The fairing covers the upstream main post and significantly diminishes the noise-producing flow interaction between the front and rear struts. Another effective concept was a streamlined, tight-fitting brake fairing that covered the smaller brake components located between the two wheels (see Fig. 9b). Although performing well acoustically, the original brake fairing concept was deemed impractical for application in a realistic environment at full scale due to brake cooling and maintenance issues. Therefore, a new fairing design that partially covers the frontal portion of the two wheels was developed. The new wheel fairing was very effective, improving upon the original brake fairing in the amount of noise that was reduced from the lower portion of the landing gear. Solid and partially porous versions of the wheel fairing (see Fig. 9c) were fabricated and evaluated during the 14 x 22 test entry. Finally, to reduce the low frequency noise associated with the wheel well (cavity), a new concept that uses a stretchable mesh to cover the cavity interface (opening) was developed and tested on the isolated Goodrich gear in the Virginia Tech tunnel. The stretchable cavity mesh performed superbly by reducing the low-frequency component of the gear noise by more than $2-3 \mathrm{~dB}$. Figure $9 \mathrm{~d}$ shows this concept installed on the $18 \%$ scale aircraft model. 


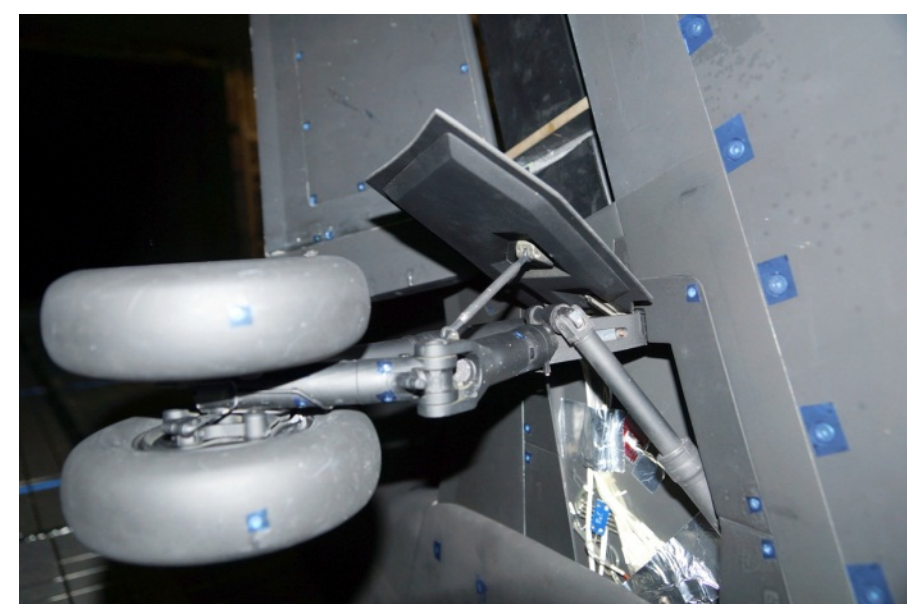

Figure 8. Frontal view of the baseline main landing (Goodrich) gear on $18 \%$ scale aircraft model.

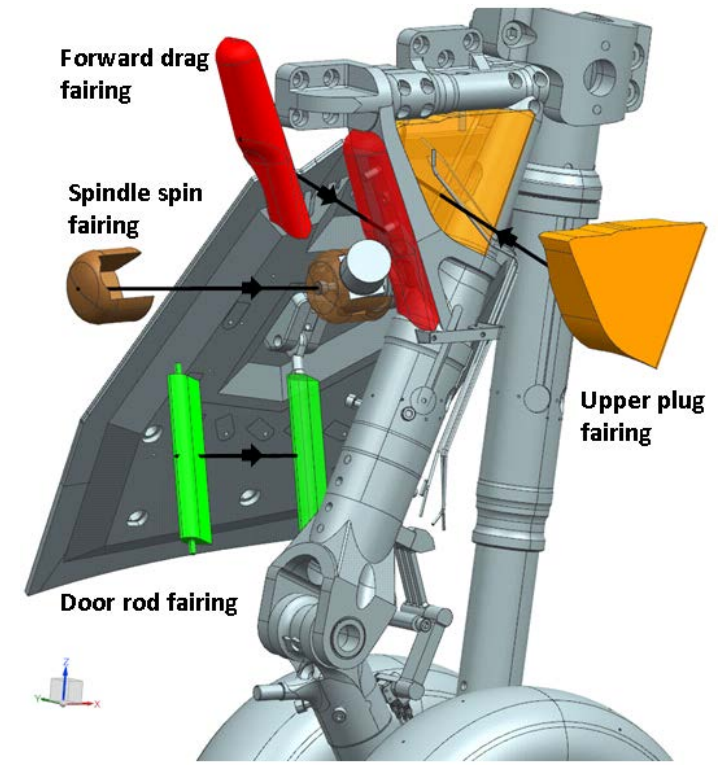

a) Upper fairings

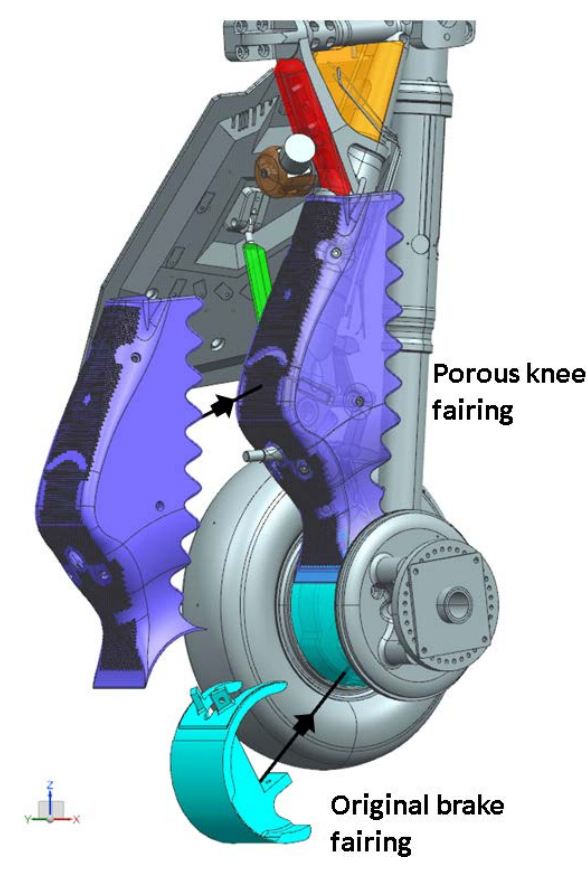

b) Porous knee and brake fairings

Figure 9. Noise reduction concepts for main landing gear. 


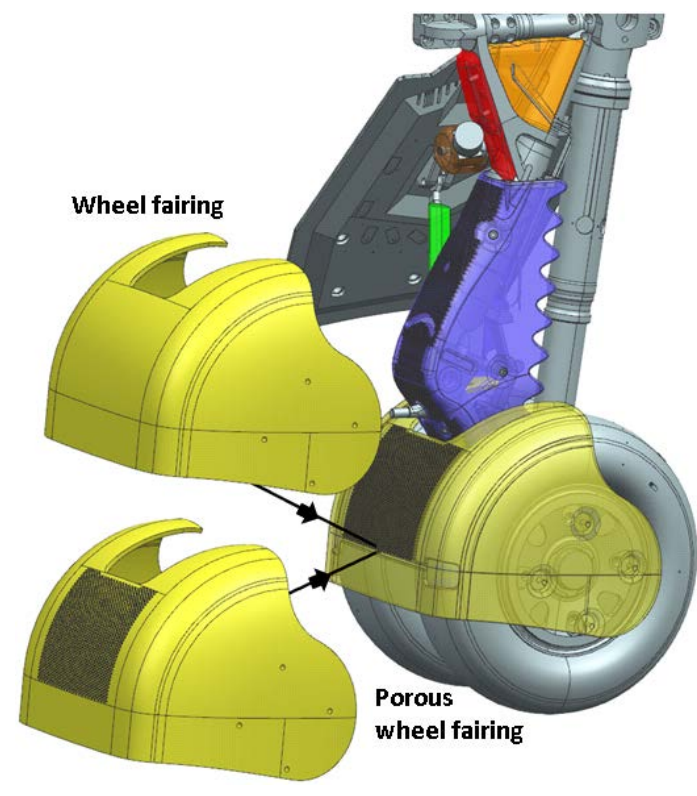

c) Solid and porous wheel fairing

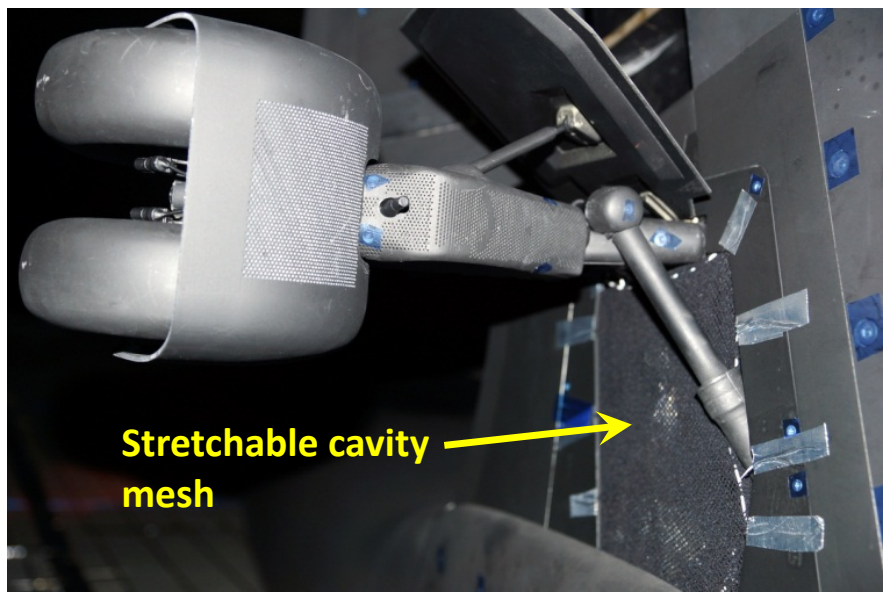

d) Stretchable cavity mesh

Figure 9. Concluded.

\section{C. $14 \times 22$ Wind Tunnel}

Acquisition of acoustic measurements and determination of the flyover directivity patterns for flap/gear noise sources required that the $14 \times 22$ facility be operated in an open-wall (jet) mode whereby the ceiling and the side walls of the tunnel test section are raised. The suitability of the tunnel open-wall mode for aeroacoustic testing was determined during the 2010 entry, when it was demonstrated that the overall aerodynamic characteristics of the 18\% scale model remained unaffected regardless of whether the measurements were conducted with the test section in a closed-wall or open-wall (jet) mode. However, operating in the open-wall mode may introduce other factors that can adversely impact the aerodynamic characteristics of the model. Changes to the tunnel test section were implemented prior to the 2013 acoustic entry. To diminish the tunnel background noise levels and to improve the quality of the measured acoustic data, the $14 \times 22$ test section was modified so that it could operate in a semianechoic acoustic mode. In this configuration the test section floor, raised ceiling, and control room blast wall were treated with sound absorbing foam wedges. The remaining side walls were covered with perforated mesh skins backed by sound absorbing foam. The floor area outside of the test section was covered with soft foam slabs. Conversion of the test section floor from a rigid to a sound absorbing surface was accomplished via the installation of metal cages containing foam wedges (see Fig. 1a). To remove voids created in the upper part of the cages containing the wedges, two inch $(5 \mathrm{~cm})$ thick slabs of soft foam were used to cover the wedges before the metallic grid defining the top side of each cage was secured in place, firmly pressing against the soft foam. The resulting test section floor was a very rough, non-uniform surface compared to the 14 x 22 standard rigid floor. The roughened surface may significantly thicken the turbulent boundary layer on the floor, thus affecting the aeroacoustic measurements. The effects of the acoustic floor on the aerodynamic characteristics of the $18 \%$ model are discussed in detail in the companion paper by Neuhart et al. ${ }^{13}$ Note, however, that the steady and unsteady pressure fields on the flap, particularly in the regions of predominant noise sources (inboard and outboard flap tips), remained unaffected.

\section{Microphone Phased Array}

The microphone phased array, constructed specifically for use in the $14 \times 22$ wind tunnel, ${ }^{19}$ consisted of 97 individual Bruel and Kjaer (B\&K) Model 4938 1/4-inch pressure field microphones attached to B\&K Model 2670 1/4-inch preamplifiers. All microphones were flush mounted (gap free) in a flat fiberglass honeycomb plate with a total diameter of $8.05 \mathrm{ft}(2.454 \mathrm{~m})$. The array was designed for an operational frequency range of approximately $1.5 \mathrm{kHz}$ to $80 \mathrm{kHz}$. This was achieved by using an irregular circular pattern of microphones (see Fig. 10) comprised of 16 array arms with 6 microphones in each arm. One microphone was positioned in the center of the array. The maximum aperture size (outermost microphone to outermost microphone) was $6.55 \mathrm{ft}$ (1.996 m), yielding a solid 
collecting angle of 21.2 degrees at a working distance of $17.5 \mathrm{ft}(5.334 \mathrm{~m})$. This angle was considered acceptable for the current study in the facility. ${ }^{20}$ The array panel, positioned at a lateral distance of $17.5 \mathrm{ft}(5.334 \mathrm{~m})$ from the tunnel centerline, was mounted to a rigid frame attached to two sets of 44 -foot $(13.411 \mathrm{~m})$ linear traversing rails manufactured by Aerotech, Inc. The traversing rails were positioned in parallel on the "south" side of the test section to allow the array to face the pressure side of the Gulfstream aircraft model (see Fig. 11). The rails were synchronized to allow smooth movement of the array panel in the streamwise direction along the full length of the test section.

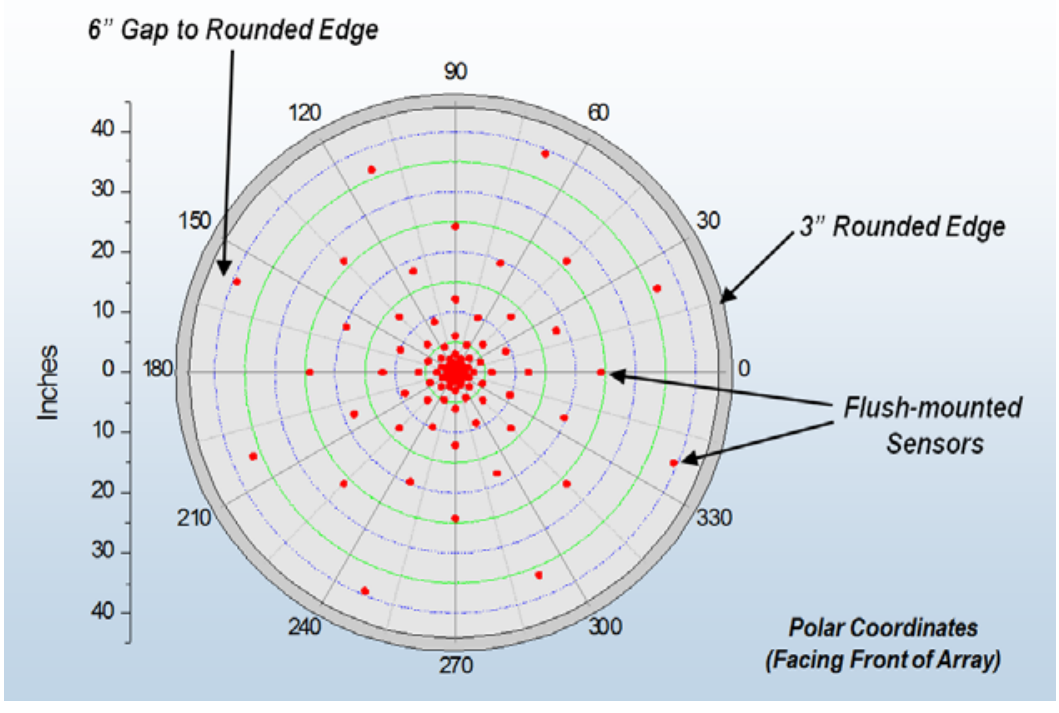

Figure 10. 14 x 22 tunnel phased array microphone pattern.

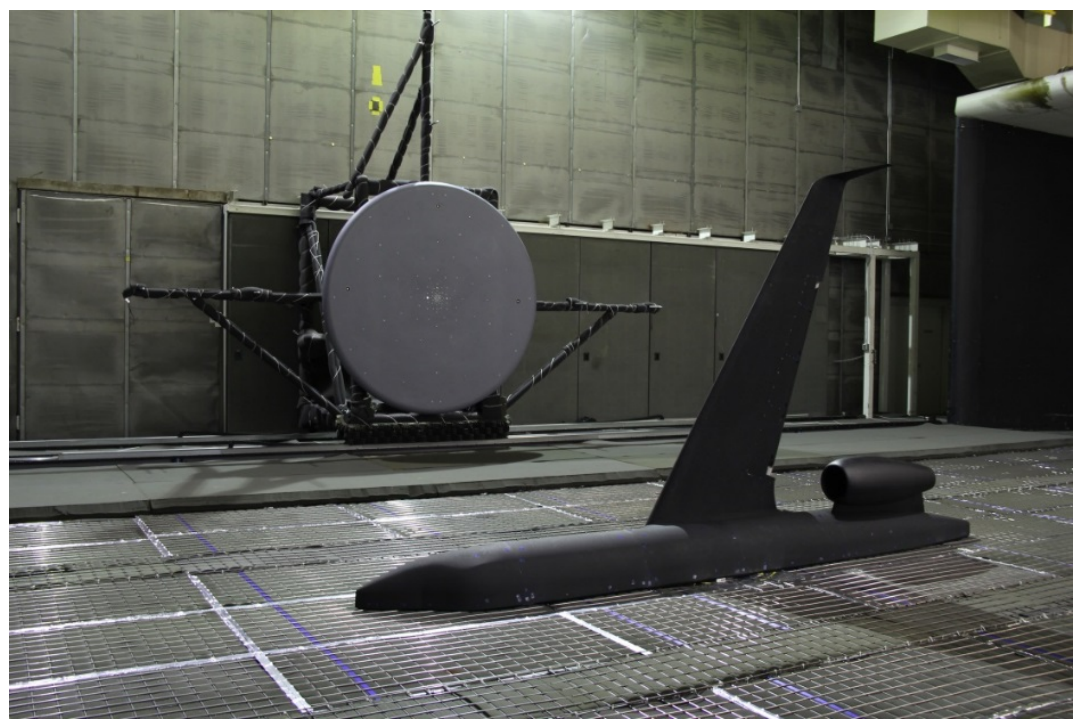

Figure 11. 14 x 22 tunnel test section showing array mounted in flyover position.

In addition, a series of six individual microphones were mounted around the phased array panel for use in characterization of noise directivity for various model configurations (see Fig. 12). The sensors consisted of B\&K Model 4138 1/8-inch pressure field microphones attached to B\&K Model 2670 1/4-inch preamplifiers by using 1/4inch to $1 / 8$-inch adapters. 


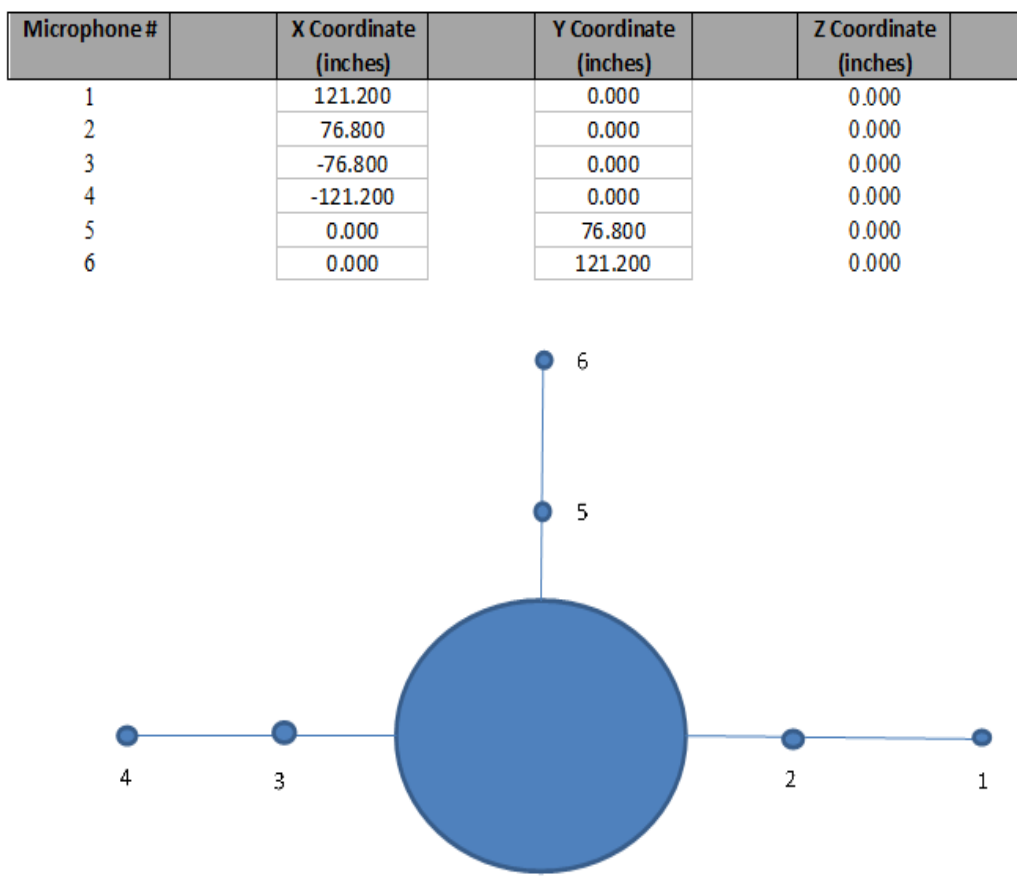

Figure 12. Layout of directivity microphones adjacent to phased array.

\section{E. Data Reduction and Analysis}

Microphone time history data were stored on high capacity network-attached storage devices as a series of individual binary data files, one file per channel. The nominal simultaneous sampling rate for all channels was 200 $\mathrm{kHz}$ for an acquisition window length of 30 seconds, with all signals band-pass filtered from $400 \mathrm{~Hz}-100 \mathrm{kHz}$. The reduction system consisted of a distributed set of computers for preprocessing of array and individual microphone data, coupled with the NASA LaRC K cluster (a high-performance, mid-range computer cluster comprised of SGI ICE-X racks) for post processing of the acquired data. Detailed analysis of array data was performed using standard frequency-domain delay and sum beamforming coupled with the Deconvolution Approach for the Mapping of Acoustic Sources (DAMAS) algorithm for generation of final noise source map presentations. ${ }^{21,22}$ A customized version of the DAMAS algorithm, called Unified DAMAS (UDAMAS), combining aspects of both the DAMAS and DAMAS-C algorithms, was executed on the $\mathrm{K}$ cluster. A hyperbolic tangent-based shading algorithm was developed and used to better control beamwidth size over the analysis frequency range. The UDAMAS code was parallelized to take advantage of the multi-core capabilities on the $\mathrm{K}$ cluster to greatly improve execution times during processing. Beamformed and deconvolved source presentation maps for standard 1/12-octave bands spanning a frequency range of approximately $500 \mathrm{~Hz}-30 \mathrm{kHz}$ were generated for the majority of the phased array datasets acquired for the Gulfstream model.

\section{Results}

Aeroacoustic testing of the model was completed in late March 2013. Given the specific interest in airframe noise during landing operations, a $39^{\circ}$ flap setting with the main landing gear alternately installed and removed were the most heavily tested configurations of the experiment. A third configuration with a retracted $\left(0^{\circ}\right)$ flap and installed gear was used to evaluate the isolated acoustic performance of the gear noise reduction concepts. To assess possible directivity effects on the performance of the noise abatement technologies, acoustic measurements were acquired at flyover directivity angles (prior to shear layer corrections) of $54^{\circ}$, and $60^{\circ}-110^{\circ}$ in $10^{\circ}$ intervals. Test section and flowfield limitations precluded obtaining measurements on a wider range of directivity angles. To elucidate potential scaling laws associated with fluctuating surface pressures and radiating acoustic fields, measurements were obtained at Mach numbers of $0.16,0.20$, and 0.24 , with 0.20 being the nominal speed at which the majority of the data were acquired. The model was set at angles of attack (AOA) of $3^{\circ}, 4^{\circ}$, and $5^{\circ}$.

The aerodynamic performance (including stall conditions) of the $18 \%$ scale model with the flap and gear noise reduction concepts installed is discussed in the companion paper by Neuhart et al. ${ }^{13}$ In that paper, the authors show 
that the changes in lift and drag coefficients for model configurations fitted with gear/flap noise abatement technologies fall within the repeatability of the baseline configuration. Thus, the concepts have no measurable detrimental impact on the aerodynamic performance of the aircraft model.

The extensive test campaign, comprised of more than 3,400 test points spread over 255 runs, produced in excess of $7 \mathrm{~TB}$ of data. Initial post processing of the entire acoustic dataset was completed recently, and careful analysis of the processed results is ongoing. Because of the large number of model configurations, model settings, and flow conditions tested, evaluation of the full dataset cannot be contained in a single report. Only a small subset of the results highlighting important aspects of the data is presented here. As such, this paper constitutes an initial glance at the measured acoustic data and our effort at providing an overall view of the major trends. More targeted assessments of each noise reduction concept will be given in future papers. In this paper, we include power spectral density (PSD) results and beamform maps from the microphone array measurements for the baseline configurations and configurations including flap/gear noise abatement technologies. The data presented here corresponds to $\mathrm{M}=$ $0.2, \mathrm{AOA}=3^{\circ}$, and a flyover angle of $90^{\circ}$. All results are based on model scale frequencies.

\section{A. Test Conditions}

Most of the data were acquired for a nominal Mach number of 0.2. At this condition, the tunnel dynamic pressure, Q, and the freestream speed are close to $57 \mathrm{psf}(2.77 \mathrm{kpa})$ and $223 \mathrm{ft} / \mathrm{sec}(68 \mathrm{~m} / \mathrm{sec})$, respectively. The corresponding unit Reynolds number is $1.343 \times 10^{6}$ per foot $\left(4.405 \times 10^{6}\right.$ per meter) resulting in a Reynolds number of $3.446 \times 10^{6}$ based on the $18 \%$ scale model mean aerodynamic chord of 30.8 in. $(0.782 \mathrm{~m})$. The freestream turbulence level in the $14 \times 22$ tunnel with the facility in the standard open-wall (jet) configuration is on the order of $0.25 \%$; there is no information on the freestream turbulence levels when the facility is operated in the open-wall acoustic mode.

\section{B. 14 x 22 Tunnel Background Noise}

The 14 x 22 wind tunnel was built in the 1970s as an aerodynamic testing facility. Over the years, it has been modified to allow aeroacoustic testing of rotary wing configurations. Under the auspices of the ERA project, significant improvements to the acoustic measuring capabilities of the tunnel have been undertaken to facilitate airframe noise testing of both conventional and unconventional aircraft configurations.

For the present test campaign, tunnel background noise was measured with an empty test section, with and without flow, employing the microphone array positioned at all the flyover directivity angles used to acquire the model acoustic signature. In addition, a series of pyrotechnic charges were detonated on the centerline of the empty tunnel in front of the array. The purpose of the detonations was to identify any significant spurious reflection paths from the location of anticipated noise sources on the model to the array (e.g., unwanted reflections from the floor, sidewalls, tunnel flow collector, etc.). Details of the acoustic analysis procedure for the pyrotechnic runs are described by Spalt et al. ${ }^{23}$ Because of the extensive acoustic treatment applied to the test section floor, sidewalls, and ceiling, analysis of the data revealed no appreciable reflection paths that would interfere with array operation.

Comparison of microphone array integrated sound pressure levels (SPL) computed over the entire measurement grid with the spectrum obtained from the individual microphone mounted at the center of the array revealed that the tunnel background noise was elevated at low and high frequencies, rendering measurements with the individual microphones unreliable for determining the absolute noise levels for the model. The higher background noise at low frequencies was thought to be caused by jet shear layer interaction with the flow collector lip, which was not acoustically treated. At high frequencies, elevated background noise was mostly due to scrubbing of the extremely rough tunnel floor, which is formed by wire cages containing sound absorbing foam wedges.

Shown in Fig. 13 are sample spectra measured with the array center microphone, and integrated spectra from the beamform map covering the entire wing region for the cruise configuration of the model. The cruise case, which corresponds to a flap deflection of $0^{\circ}$ and gear off, represents the quietest airframe configuration, which is typically used to determine the maximum noise reduction levels attainable. Note from Fig. 13 that the integrated spectra for the empty tunnel (solid black line) and the model in the cruise configuration (dashed double dotted green line) ${ }^{* *}$ are very similar below $15 \mathrm{kHz}$, indicating that the tunnel background noise is significantly higher than that associated with the model. This questioned the suitability of the signal to noise ratio attainable in the $14 \times 22$ tunnel and whether the available range was sufficient to properly determine the full extent of the acoustic performance of the noise reduction concepts. The integrated spectra for the three configurations being used as baselines are plotted

\footnotetext{
${ }^{* *}$ Note that the beamform integrated spectrum for cruise contains a tone at $24,000 \mathrm{~Hz}$. This tone is also present in many of the PSD plots. Although its source is not known at this time, this feature appears in the clean configuration and therefore is not related to either the flap or the main landing gear.
} 
against the empty tunnel noise levels in Fig. 14. Notice that for most of the frequency range of interest, the levels associated with the baseline configurations are at least $10 \mathrm{~dB}$ above the tunnel noise floor. Such a difference in levels provided sufficient signal to noise ratio to evaluate the acoustic performance of the various noise reduction technologies investigated during the present test campaign.

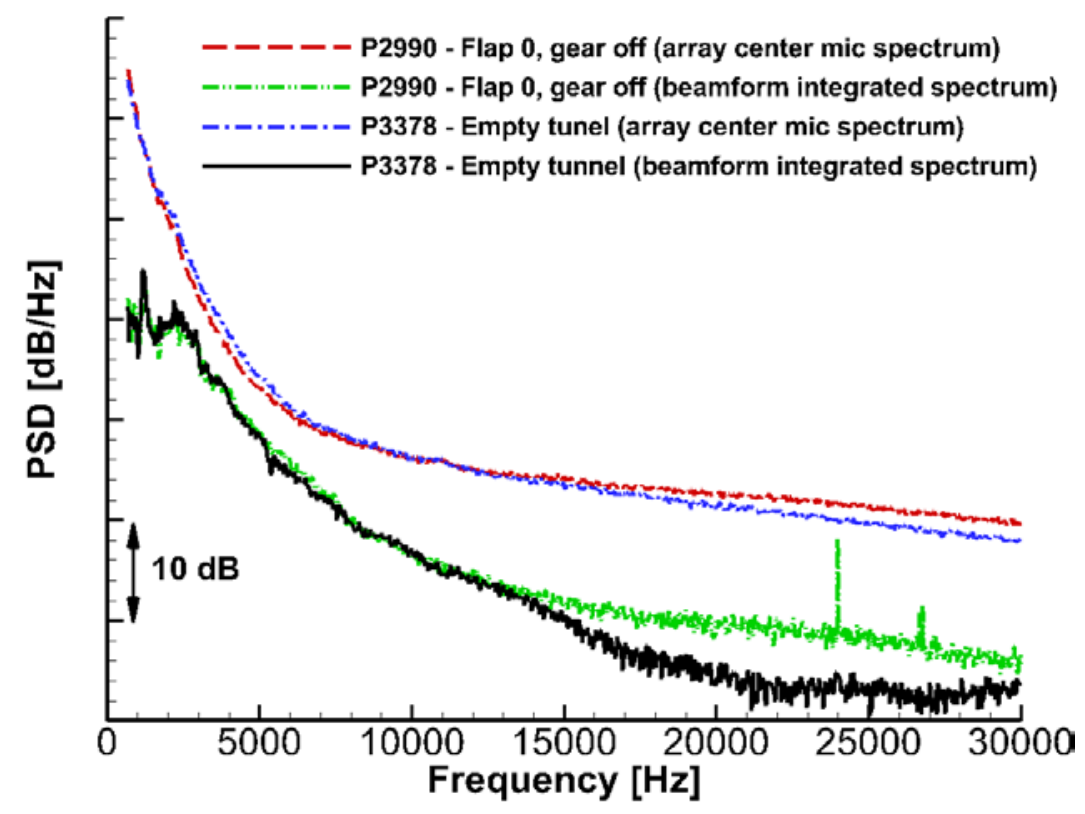

Figure 13. Comparison of integrated noise levels for empty tunnel (background noise) and model in cruise configuration. Also shown are levels obtained from the center microphone in the array.

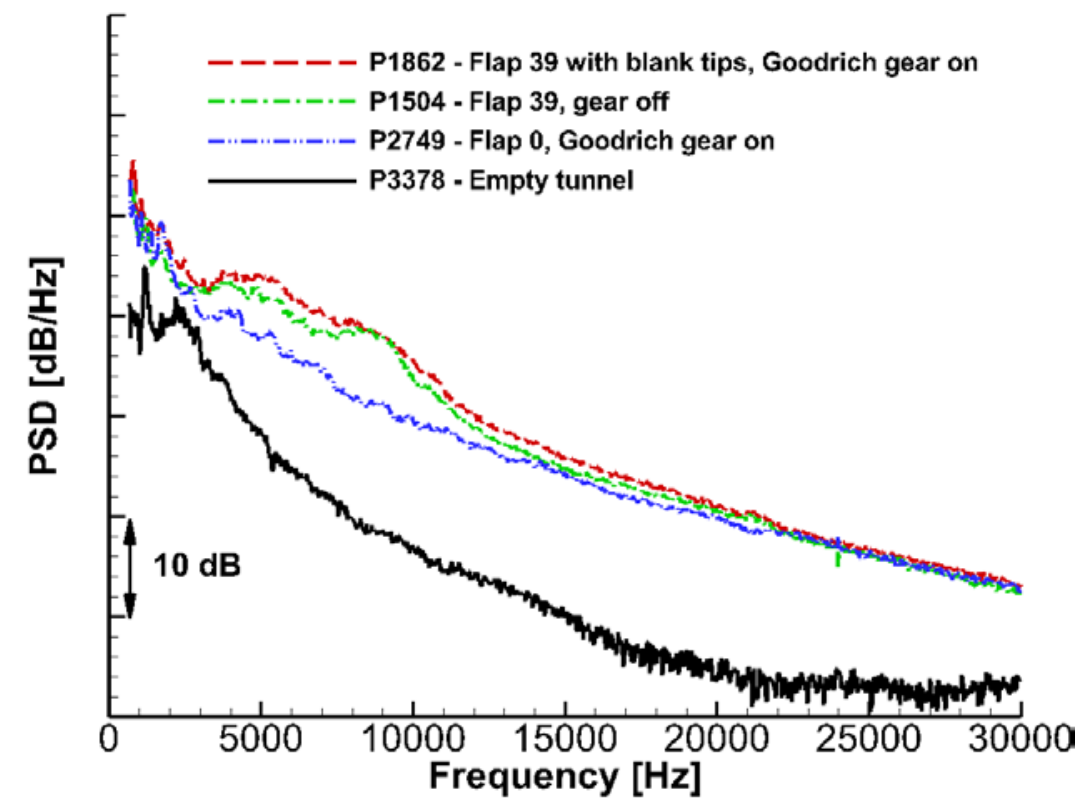

Figure 14. Comparison of integrated noise spectra for baseline configurations and empty tunnel.

\section{Flap Brackets}

The initial stages of the test campaign were devoted to establishing and documenting the appropriate baseline configurations (in terms of noise levels) for the flap and main landing gear components in isolation and when deployed simultaneously. Initial evaluation of the flap noise reduction technologies revealed a peculiar trend. Inspection of the noise spectra indicated that, while each tested concept produced differing levels of noise reduction 
at low and high frequencies, they all provided nearly identical noise levels in the mid-frequency range. That is, at moderate frequencies, a common noise floor had been reached. Analysis of the beamform maps from the microphone array indicated that the four flap brackets, and in particular the two middle brackets, were acting as prominent secondary noise sources. This was a surprise discovery, since the high-fidelity, highly resolved supporting unsteady simulations ${ }^{24,25}$ that preceded the $14 \times 22$ test had not revealed bracket noise to be of any consequence. Two wiring/tubing bundles (containing the electrical wires and pressure tubes associated with flap instrumentation) adjacent to the middle brackets were the main cause of the excess noise. We used the AVEC, Inc. phased array software ${ }^{\dagger \dagger}$ to quickly analyze the microphone array results in near real time during testing. This enabled configurations to be investigated rapidly, allowing us to identify the source of the extraneous noise and assess several mitigation strategies. It was apparent that the spanwise flow within the wing cove area and the close proximity of the instrumentation bundles with the two middle brackets had combined to create noise-producing flow interactions. Since neither the bundles nor the brackets could be moved from their existing locations, other solutions had to be explored.

A series of tests was performed with the tubing bundles and brackets wrapped with a thin sheet of ordinary soft foam. The best solutions were determined to be soft foam wrapping of a) the two instrumentation bundles and b) the two instrumentation bundles plus the second bracket from the flap inboard tip. Attempts to cover additional brackets resulted in significant alteration of the flap aerodynamic characteristics, in particular at the outboard tip. As a result, nearly all subsequent acoustic measurements (with and without noise reduction concepts installed) had at a minimum two cable bundles wrapped with soft foam.

\section{Beamform Maps}

Beamform (or source localization) maps are useful in determining the location and relative strengths of prominent airframe noise sources. The noise contours in the maps shown here were normalized by subtracting the maximum (peak) level in each map from the sound levels in that map. All results presented in this section where obtained with the array in the $90^{\circ}$ overhead position. The maps constructed for the baseline landing configuration with flaps deflected $39^{\circ}$ and main landing gear on at AOA $=3^{\circ}$ are shown in Fig. 15. For comparison purposes, 1/12octave noise contour maps at the model-scale center frequency of $6,700 \mathrm{~Hz}(1,200 \mathrm{~Hz}$ full scale) from both conventional delay and sum beamforming and UDAMAS processing are presented. The beamforming was performed with a frequency bin width of $24.4 \mathrm{~Hz}$. Seven adjacent bins were combined to form narrow band results with a bin width of $171 \mathrm{~Hz}$. One-twelfth octave results were calculated by combining the narrow band data. The conventional beamform map clearly shows the outboard flap tip to be the dominant noise source at this frequency, closely followed by the sources associated with the main gear and inboard flap tip. Due to the close proximity of the gear to the inboard flap side edge, the peak level region in the map covers both sources without any clear indication as to which is more pronounced. A better resolved representation of the noise sources emerges from the map constructed using the UDAMAS approach. In this representation, the noise sources residing at or near the inboard tip are clearly separated, with the highest SPL being associated with the main gear.

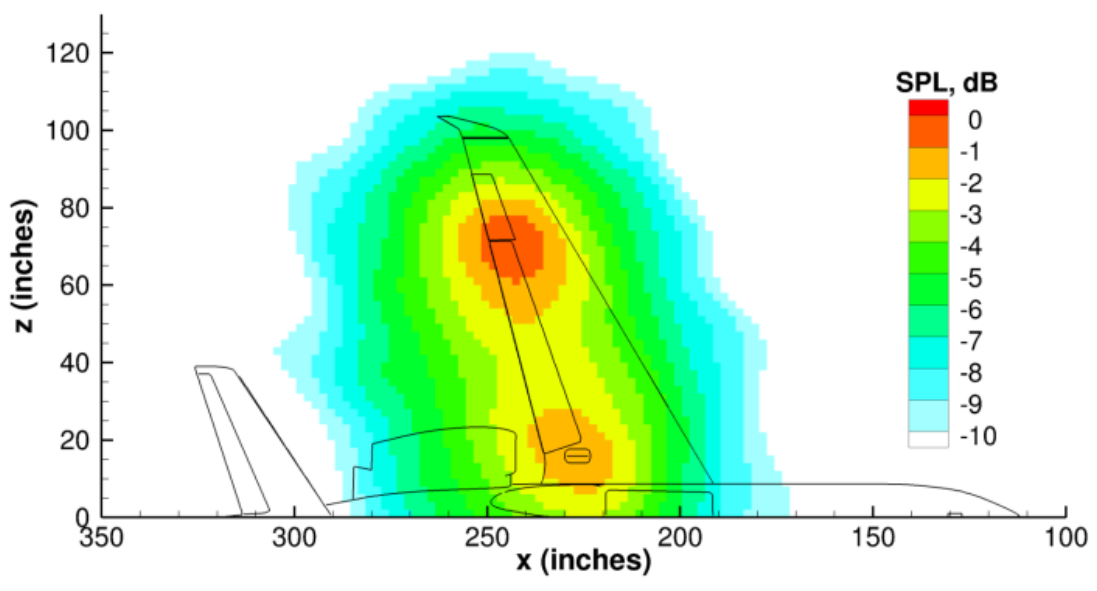

a) Conventional beamforming.

Figure 15. Noise contour maps from microphone array for landing configuration at $6,700 \mathrm{~Hz}$ and $\mathrm{AOA}$ of $3^{\circ}$.

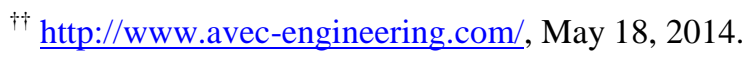




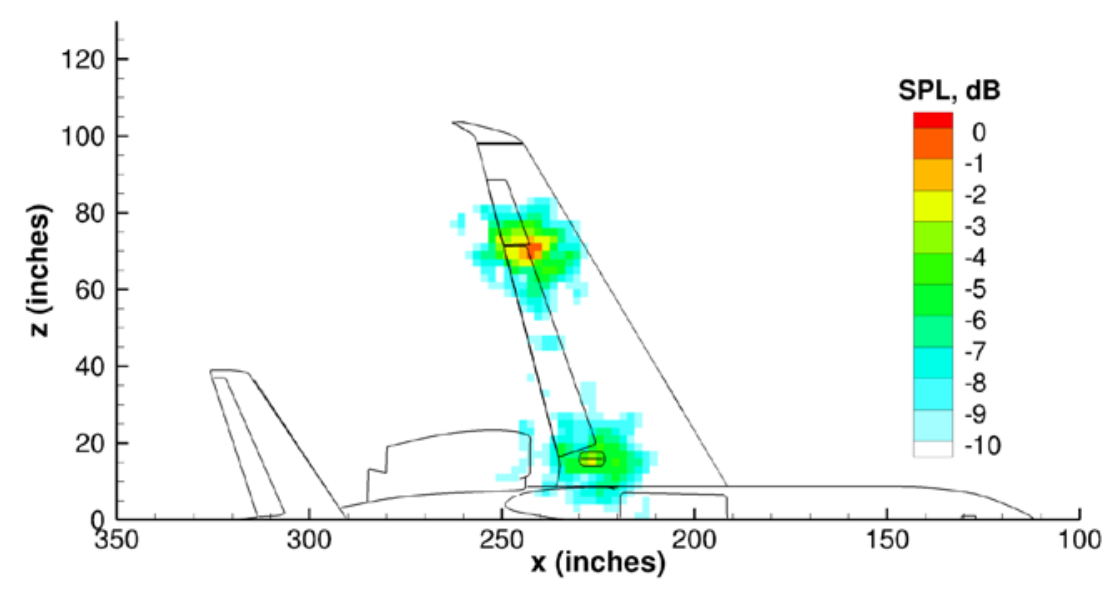

b) UDAMAS

Figure 15. Concluded.

Initial screening of the flap noise reduction concepts was accomplished on a model configuration that isolated the flap noise sources. This baseline configuration consisted of a $39^{\circ}$ flap deflection, the main landing gear removed, and the model at $3^{\circ}$ AOA. The UDAMAS generated contour map at $6,700 \mathrm{~Hz}$ is plotted in Fig. 16. Both flap tips appear as major noise sources with the maximum SPLs at the outboard tip being nearly $8 \mathrm{~dB}$ above the inboard levels. Applying the FLEXSEL concept to both tips (see Fig. 6) produced a significant reduction in the noise levels. The UDAMAS generated contour map for the FLEXSEL configuration is shown in Fig. 17. Notice that the outboard tip is no longer a "hot spot" with the sources at the inboard tip becoming much more prominent. The SPL values at the inboard tip also experience a noticeable drop with the application of the FLEXSEL concept. However, the magnitude of the reduction is not as pronounced as that achieved for the outboard tip. Also note that with the reduction in SPLs at both side edges, other sources on the flap are now apparent. These additional sources are mainly associated with the four flap brackets and the two bundles of instrumentation wiring that run from the flap to the main wing.

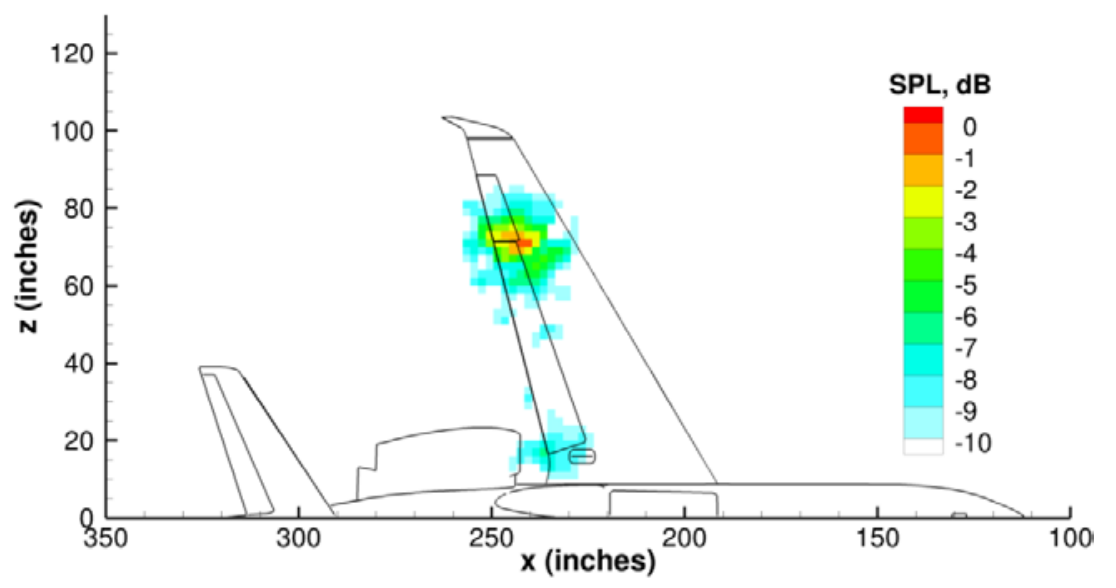

Figure 16. UDAMAS noise contour map for $39^{\circ}$ flap and gear off configuration at $6,700 \mathrm{~Hz}$ and $3^{\circ} \mathrm{AOA}$. 


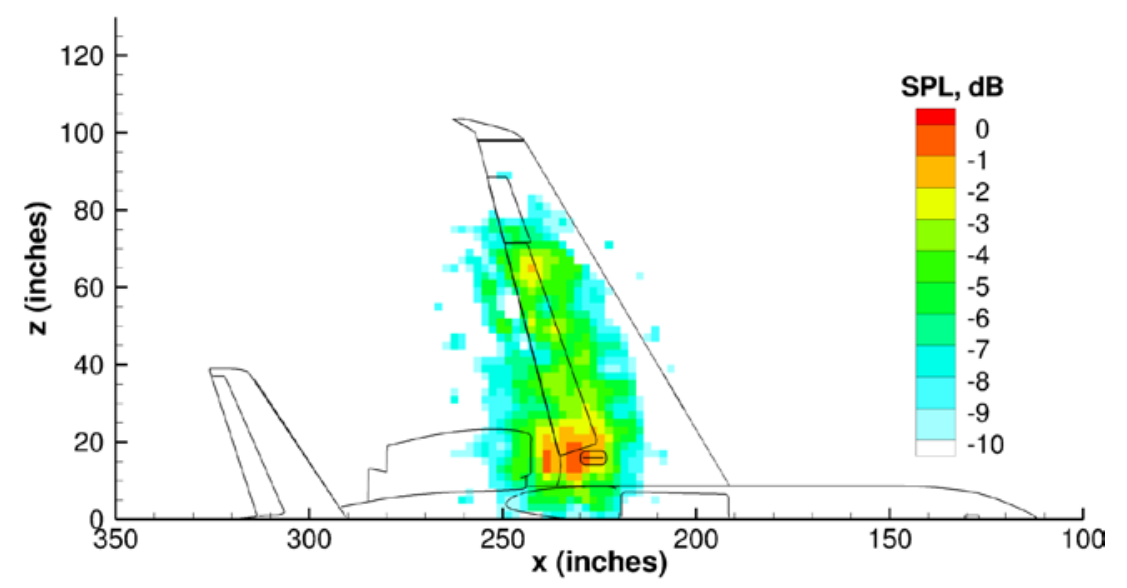

Figure 17. UDAMAS Noise contour map with FLEXSEL concept installed on $39^{\circ}$ flap and gear off configuration at $6,700 \mathrm{~Hz}$ and $3^{\circ} \mathrm{AOA}$.

\section{E. Power Spectral Density}

A convenient approach to determine the characteristics of airframe noise sources and to evaluate the effectiveness of a particular noise reduction concept is to examine PSD plots in conjunction with noise contour maps. Construction of the PSD curves requires an accurate spatial integration of the pressure squared values in the contour maps at select frequencies. The frequency resolution for the narrow band calculation of the spectra is 171 Hz. Depending on the nature of the model tested and the information to be gleaned, different integration zones could be utilized. For the present case, four integration regions have been devised as shown in Fig. 18. Region 1 covers an area that contains all the prominent airframe noise sources of interest. Regions 2 and 3 were specifically devised to ascertain 1) the individual contributions from the flap tips to the overall noise levels and 2) whether a particular flap noise reduction technology is equally effective at both edges. Region 4 covers the entire aircraft model, facilitating direct comparisons with the companion computational simulations. ${ }^{24,25}$ In this paper we present PSD results obtained from integrating the UDAMAS contour maps over the entire aircraft (Region 4). Results based on Regions 1, 2, and 3 will be presented at a later date.

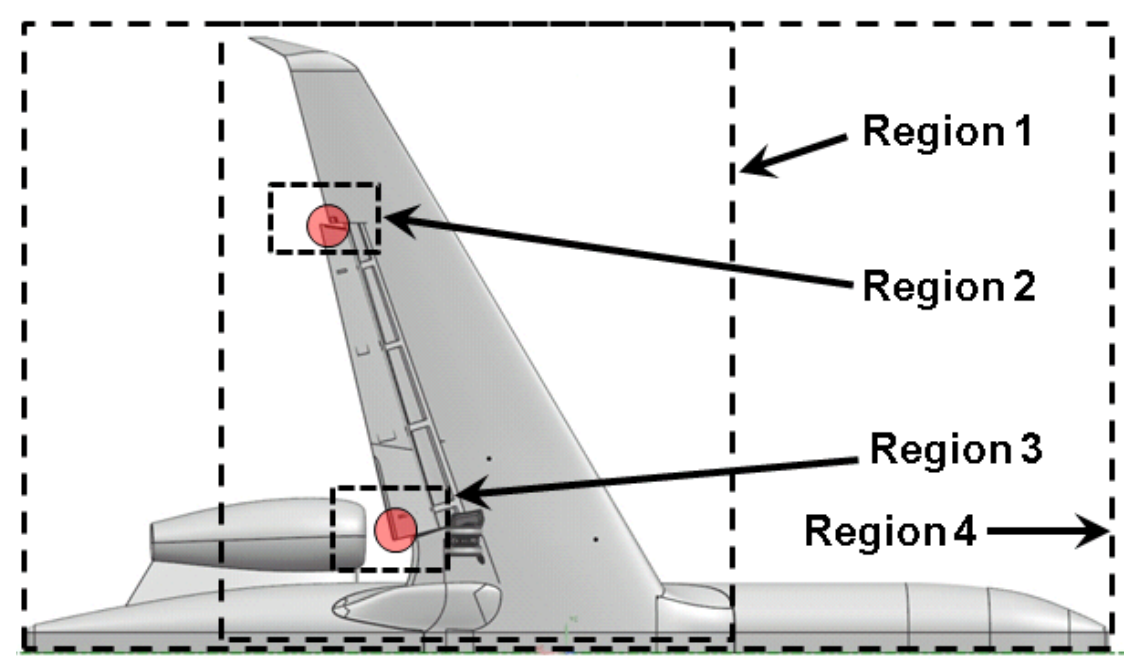

Figure 18. Integration zones used to calculate PSD values.

\section{F. Reduction of Flap Noise}

The configuration with $39^{\circ}$ flap deflection and gear off was used to evaluate the noise reduction potential of various low noise concepts. As discussed earlier, the instrumentation cable bundles and the flap brackets were determined to be important (albeit secondary) noise sources. Treatment of these structures with thin sheets of soft foam reduced the noise of the baseline configuration in most instances. However, it may have introduced other 
factors that made run-to-run or day-to-day variability in the measured noise levels difficult to understand or eliminate. To alleviate this problem, we chose to create an average PSD spectrum from all the available baseline flap runs that were deemed appropriate. For the purposes of this discussion, the term baseline flap refers to the flap configuration with a set of duplicate, un-instrumented replacement (also referred to as "blank") tips instead of the original instrumented ones.

The PSD spectra associated with the baseline flap runs used to obtain the average are shown in Fig. 19. Note from the figure that run-to-run variability in the measured noise levels starts at $16 \mathrm{kHz}$ and worsens with increasing frequency. Observe also the existence of day-to-day variations (P1504 vs. P1780) even when the instrumentation cables and the second bracket from the inboard tip were covered with foam. However, the averaged spectrum provides a reasonable baseline for a proper evaluation of the relative merit of the tested noise reduction technologies. Residual noise from the cables and brackets may preclude obtaining a true estimate of the effectiveness of each concept. Therefore, the noise reduction results shown in this paper can be viewed as being conservative (i.e., the minimum possible reduction).

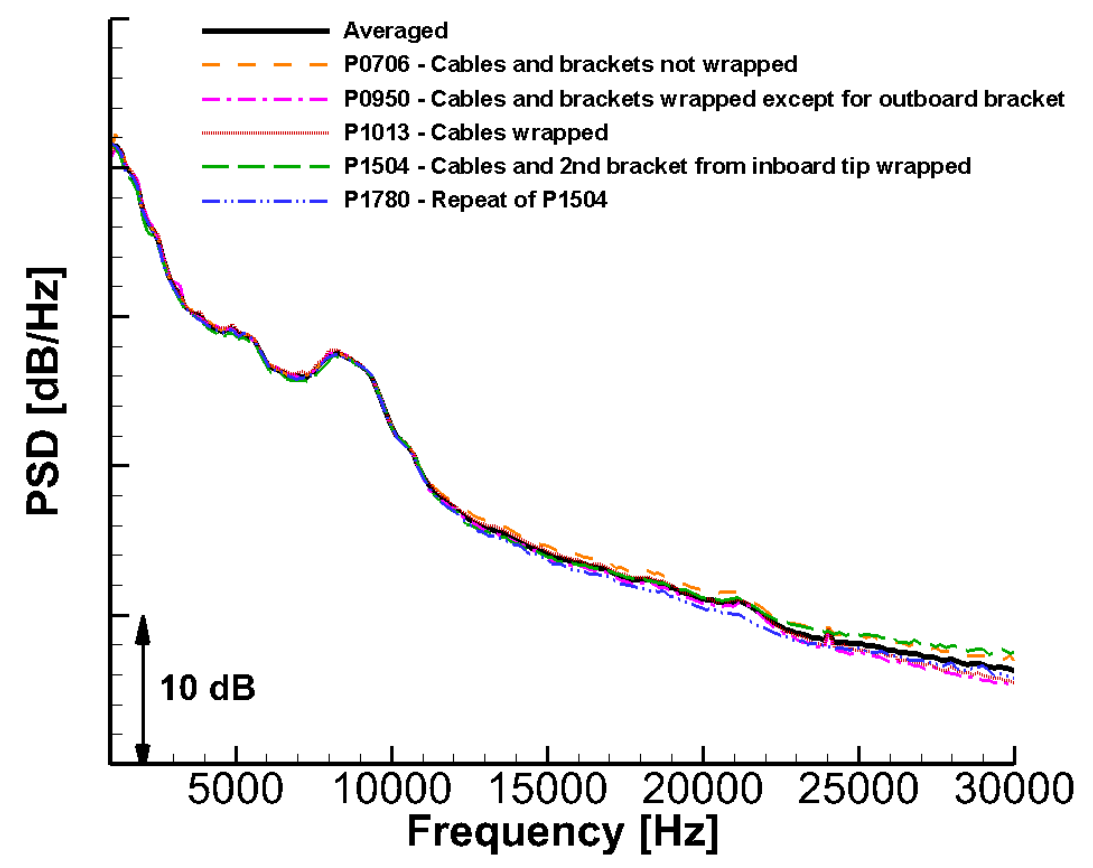

Figure 19. Points used to determine averaged flap baseline noise spectrum.

In Fig.19 notice the presence of a broad tonal feature in the $3-11 \mathrm{kHz}$ frequency range. Similar tonal behavior at the corresponding full-scale frequencies was also measured during the 2006 flight test; it was attributed to the flow-cavity interaction at the outboard tip. To assess the contribution of the outboard tip cavity to the overall farfield noise signature, acoustic measurements were acquired using a straight edge outboard tip without a cavity. A comparison of the PSD spectra for the configurations with and without the cavity at the outboard tip is presented in Fig. 20. The complete disappearance of the tonal feature clearly points to the tip cavity as the underlying source. Notice from the figure that the standard straight edge tip produces significantly more noise at frequencies above 11 $\mathrm{kHz}$. Viewed in full scale, this frequency range is important regarding human annoyance to perceived noise. The results shown in Fig. 20 demonstrate that cavities or other types of depressions at the flap tips may have a mixed effect on the perceived farfield noise. They also raise an important question as to which PSD curve should serve as baseline. For the remainder of this paper, because of geometric fidelity, we have chosen the averaged PSD levels corresponding to the outboard tip with the cavity as the baseline for evaluating the acoustic performance of flap noise reduction concepts.

The PSD spectra for the porous treatment (skin) are plotted in Fig. 21. Results from the four tip sets with nominal treatment area are displayed. This concept reduced the noise levels significantly over the entire frequency range of interest. Although difficult to discern from the figure, the lowest evaluated skin resistance (150 Rayl) produced the best noise reduction levels, with each successive increase in resistance providing slightly less benefit. Also plotted on Fig. 21 are results from the reduced-area porous tip. This permutation provided marginally less noise 
reduction benefits at lower frequencies, where noise from the inboard tip dominates ${ }^{24}$ and constitutes a sizable portion of the overall sound pressure level (OASPL). At medium to high frequencies, the reduced-area porous tip performed at least as efficiently as any of the porous tips with nominal treatment area. For a proper assessment of acoustic performance, more weight should be given to the amount of noise reduction produced in the mid- and/or high- frequency ranges, since they heavily affect the calculation of perceived noise levels (PNL). For this reason, the OASPL should not be the sole metric used in determining the relative merits of a given noise reduction concept. In addition, some form of frequency-weighted overall level, such as A- or D-weighting standards, should be used.

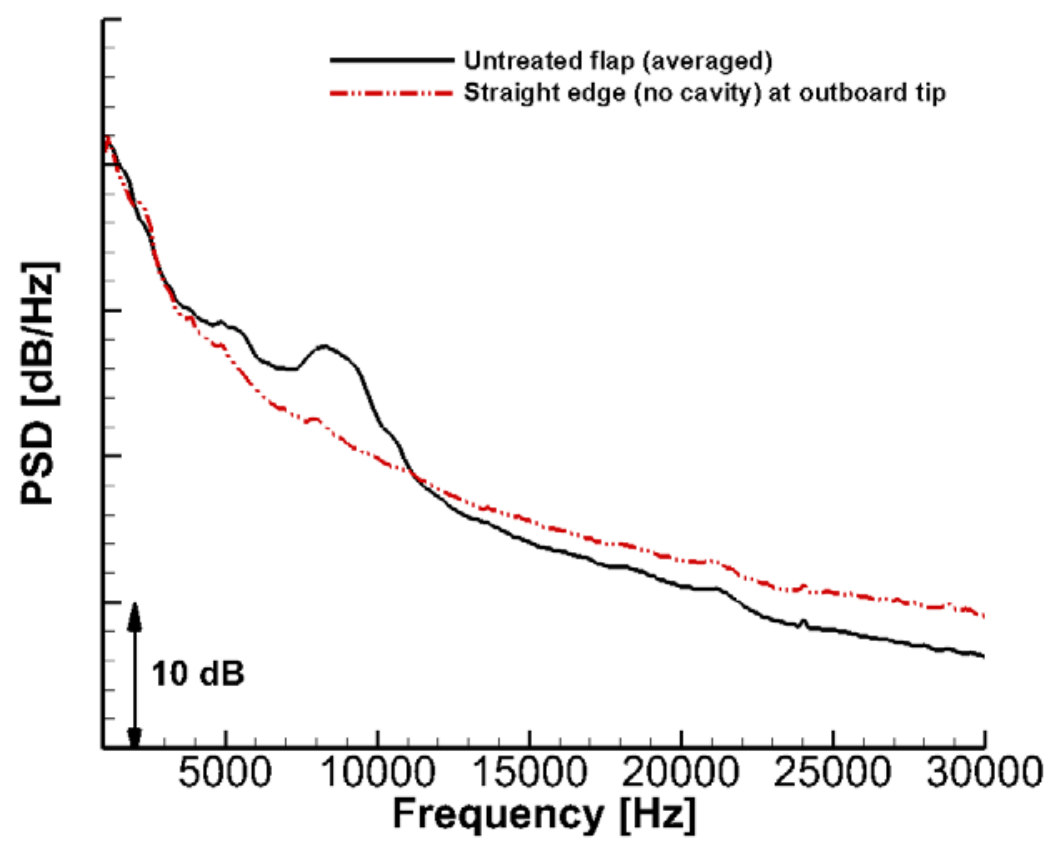

Figure 20. Power spectral density for configurations with/without outboard tip cavity.

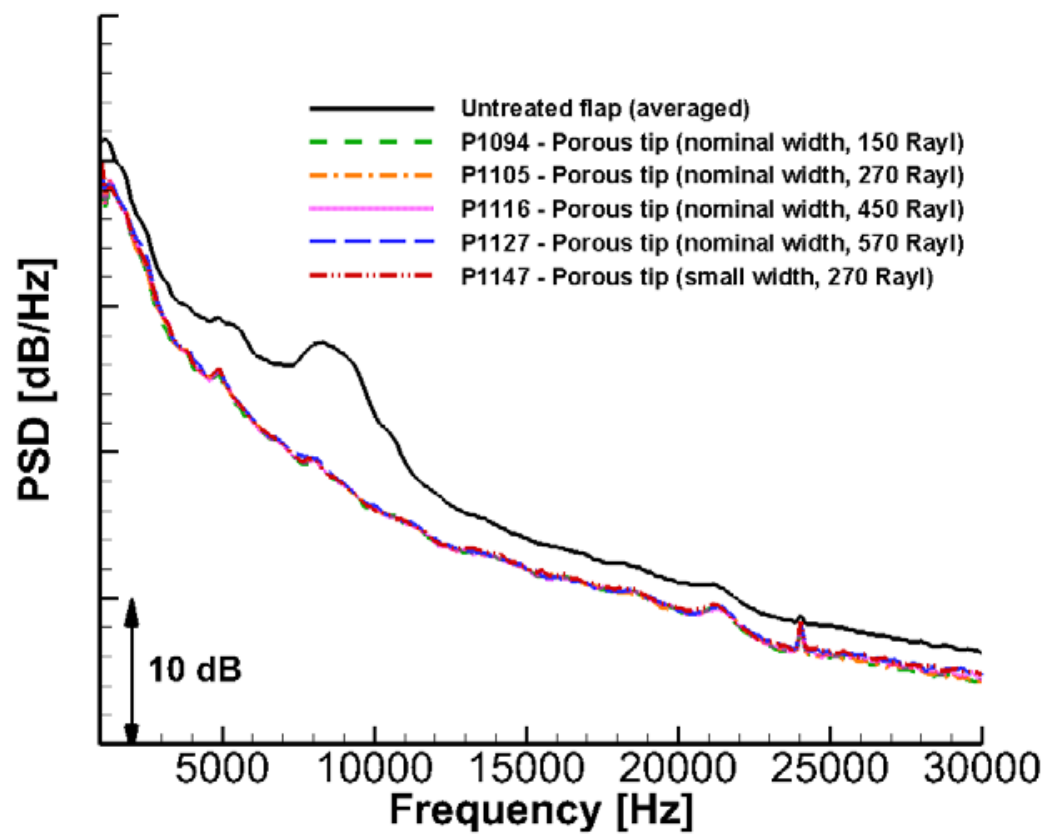

Figure 21. Power spectral density for porous skin treatments. 
The noise reduction performance of the tested acoustic liners is shown in Fig. 22. The three bulk liners provide significant reduction ( $3 \mathrm{~dB}$ or more) over most of the frequency range. This class of liners performs slightly better than the porous tip treatment. In terms of overall noise reduction capability, the bulk liners produced the largest benefits among all the concepts tested. The locally reactive liner with serpentine passages (holes) also yielded measurable noise reduction for frequencies between $3-23 \mathrm{kHz}$. However, relative to other liners, the reductions obtained with this concept are modest. Notice that this concept does not reduce noise for frequencies below $3 \mathrm{kHz}$. This suggests that low-frequency noise from the flap inboard tip is not being affected by this treatment. Recall that the locally reactive liner tested on the $18 \%$ scale aircraft model is not an optimal design due to the limited volume available at the tips. Transition to a full scale environment would relax this constraint, allowing the pursuit of further improvements to the concept.

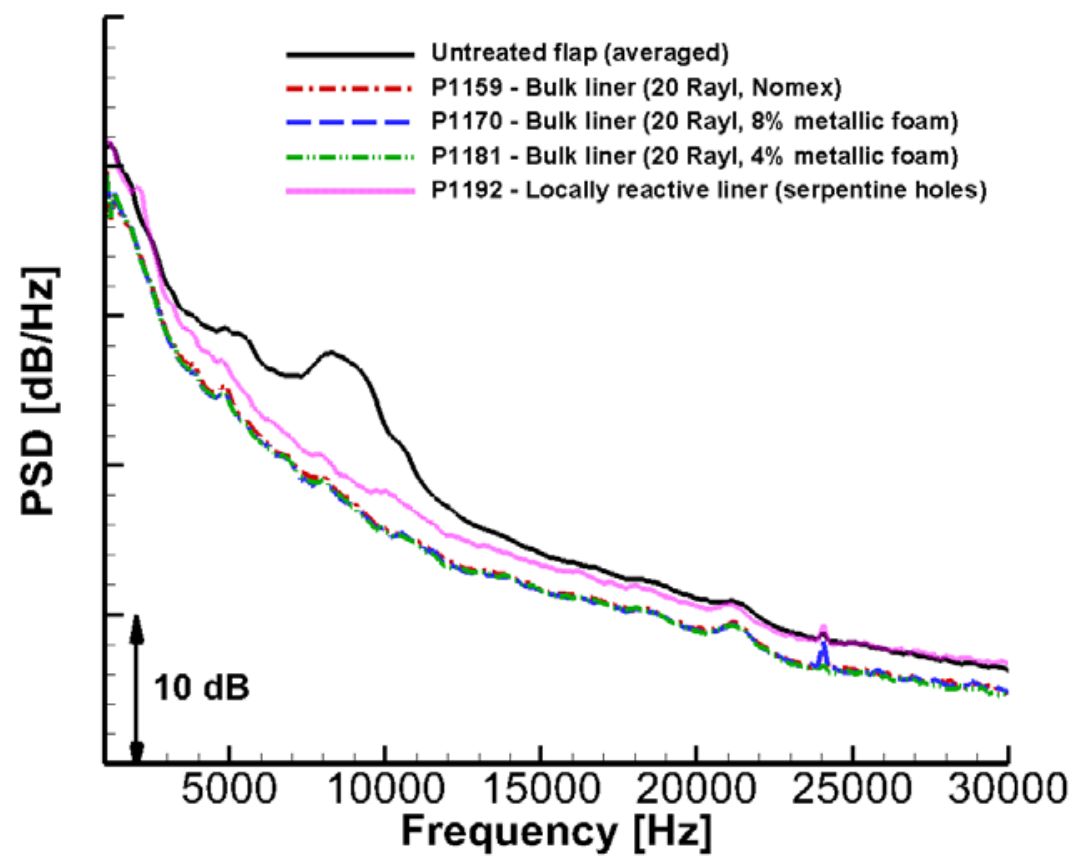

Figure 22. Acoustic performance of liner concepts.

Comparative PSD results for the FENoRFins are plotted in Fig. 23. The large width, non-circular cross-section fins provided substantial noise reduction at frequencies below $5 \mathrm{kHz}$. Above this frequency the PSD spectra begin to level off, crossing the baseline (untreated) flap curve around $9 \mathrm{kHz}$. For higher frequencies, the large non-circular fins produced significantly more noise than the untreated flap. This excess noise is directly attributable to the concept; throughout this paper, it will be identified as "device noise." The small width non-circular fins yielded similar noise reduction benefits at lower frequencies while shifting the location where the PSD curve crosses the baseline spectrum to approximately $11 \mathrm{kHz}$. Compared to the large width fins, the concept with the small width fins generated significantly less device noise. The circular cross-section fins provided increasingly better noise reduction with decreasing fin diameter by lowering device noise and shifting the cross-over point to higher frequencies. Because of time and cost constraints associated with production of this concept, the tested samples were fabricated using a narrow range of normalized fin spacing. This range was selected, after giving careful consideration to several competing parameters, to provide the best compromise. As such, the results presented in Fig. 23 should be regarded as preliminary. The concept can be improved by incorporating a smaller fin spacing to reduce significantly the device noise at higher frequencies; this would drop the PSD levels below the baseline values over most of the frequency range. Full-scale testing of the concept would also reduce device noise. Assuming that circular crosssection FENoRFins maintain their full functionality when sized for a relevant full scale environment (e.g., Reynolds number effects are insignificant), a geometrical scaling factor slightly smaller than the current 5.56 (18\% scale) could be used in the full-size design. Using this approach, the cross-over frequency where device noise exceeds baseline noise could be maintained above $7-8 \mathrm{kHz}$ and thus not be a factor in airframe noise considerations. 


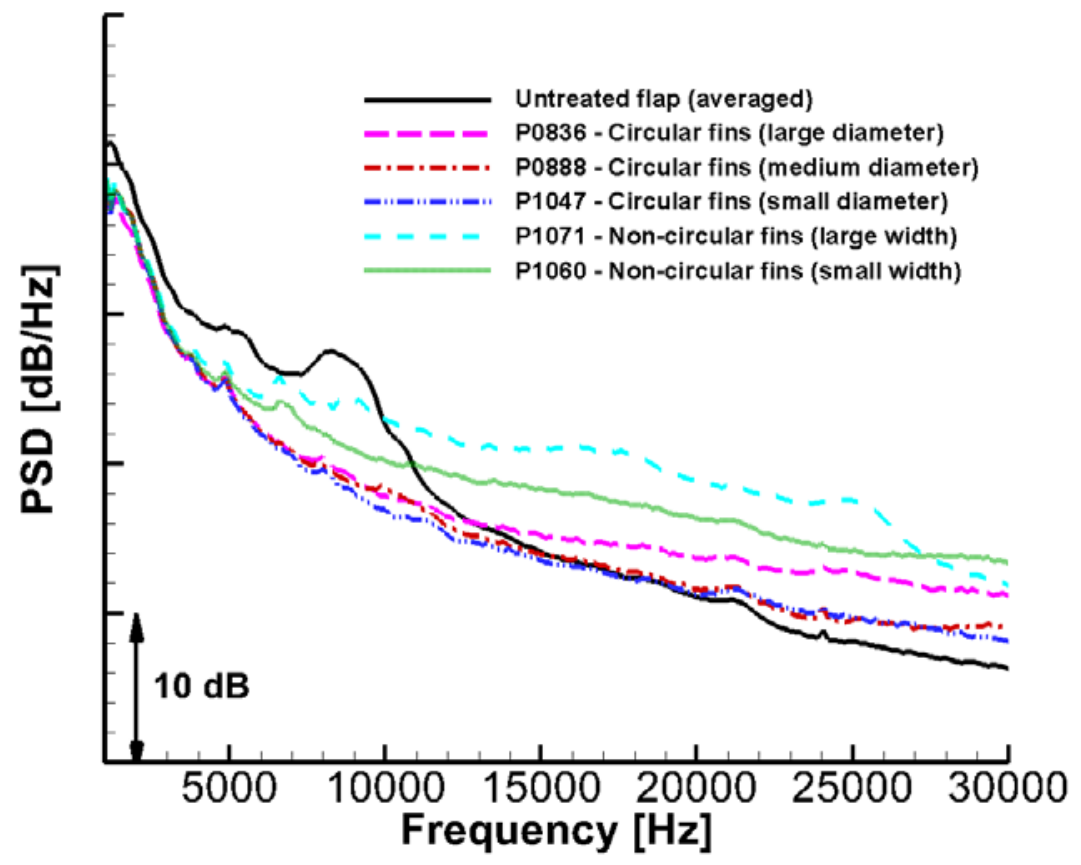

Figure 23. Acoustic performance of FENoRFins.

The noise reduction performance of the FLEXSEL concept is shown in Fig. 24 for both soft and rigid versions of the design. Initial testing of the soft FLEXSEL (P1212 curve) revealed excess noise at certain frequencies due to surface imperfections created by the casting process used during hardware fabrication. Judicious application of thin aluminum tape eliminated the excess noise. As can be seen from the figure, the taped soft FLEXSEL (P1227) produced noise reduction levels, over the entire frequency range, that were slightly better than those corresponding to the rigid version of the design. We attribute this marginal improvement in performance to the surface compliance of the soft FLEXSEL, which provides an additional damping effect on the fluctuating surface pressure field. Further examination is required to assess the validity of this conjecture. Note from Fig. 24 that the noise reduction capability of FLEXSEL diminishes gradually with increasing frequency above $14 \mathrm{kHz}$; at $25 \mathrm{kHz}$, the PSD levels approach those of the baseline configuration. Also shown in Fig. 24 is the spectrum obtained with the larger width FLEXSEL. Starting at $3 \mathrm{kHz}$, the measured PSD curve for this version displays significantly higher noise levels (in excess of 2 $\mathrm{dB}$ ) than those obtained with the rigid and soft FLEXSELs of nominal width. Unless the loss in acoustic performance is the result of an increase in the noise being produced by the instrumentation cables and flap brackets (caused by changes in the spanwise flow within the wing cove), we do not have a clear explanation for this behavior The effectiveness of the larger width FLEXSEL could be determined via high-fidelity computational simulations similar to those discussed in Refs. 24 and 25. This would be a worthwhile pursuit, since among all the flap concepts tested, FLEXSEL was the only one that showed a measurable improvement in the aerodynamic performance (i.e., lift coefficient) of the $18 \%$ scale aircraft model.

The noise reduction capability of the ROLD concept is shown in Fig. 25. This treatment provided substantial benefits at low to moderate frequencies. At high frequencies, the concept displayed characteristics similar to those of FENoRFins, with significant device noise that decreased with decreasing hole diameter. Unfortunately, the initial set of runs (P0800, P0812, and P0824) was made prior to identification of the interaction noise between the cable bundles and the flap brackets. Subsequent testing with foam wrapping on the cable bundles was limited to the best performing ROLD design (small diameter holes). The PSD data for this configuration (P1036) are also plotted in Fig. 25 and show significant improvement over the unwrapped configuration (P0824) for frequencies above $16 \mathrm{kHz}$. As is evident in this figure, even with improved performance at higher frequencies, the device noise penalty associated with this concept is noticeable. With regard to this lingering device noise, we cannot determine whether it is caused by scrubbing as the flow passes over the rough surface created by the holes, or if it is caused by flow ejection/suction out of/into the perforations. 


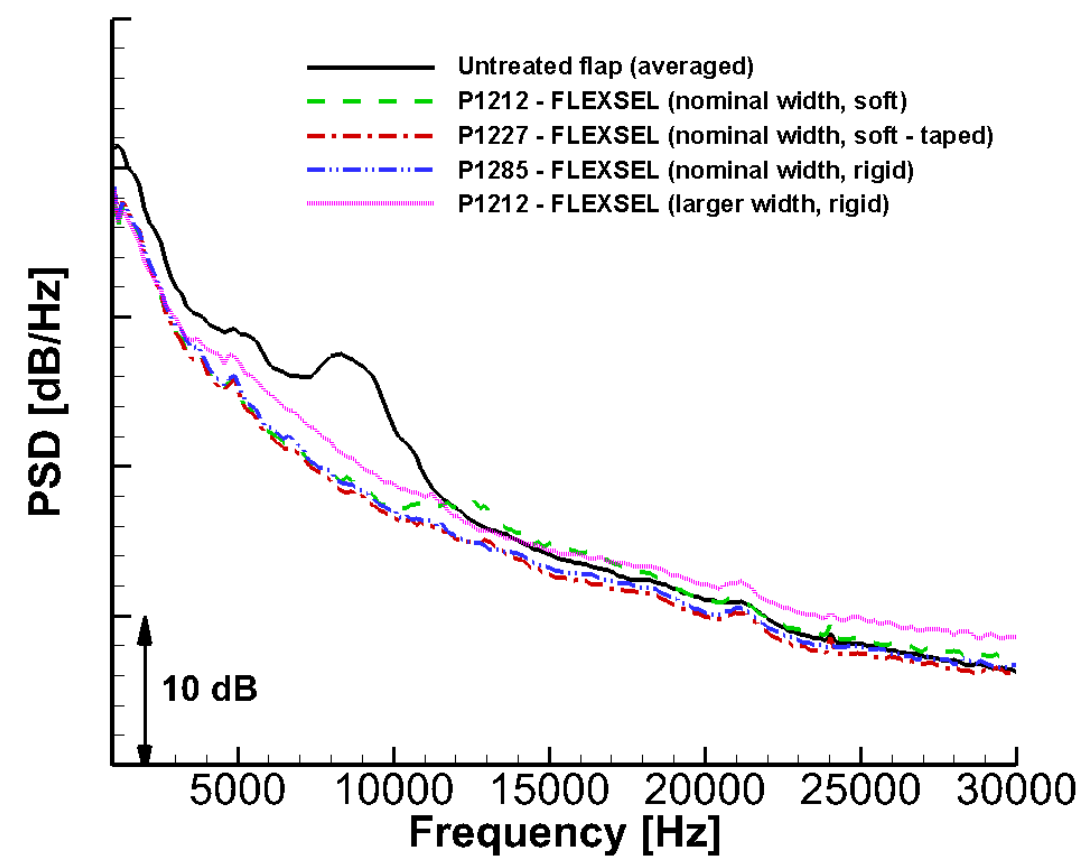

Figure 24. Acoustic performance of FLEXSEL concept.

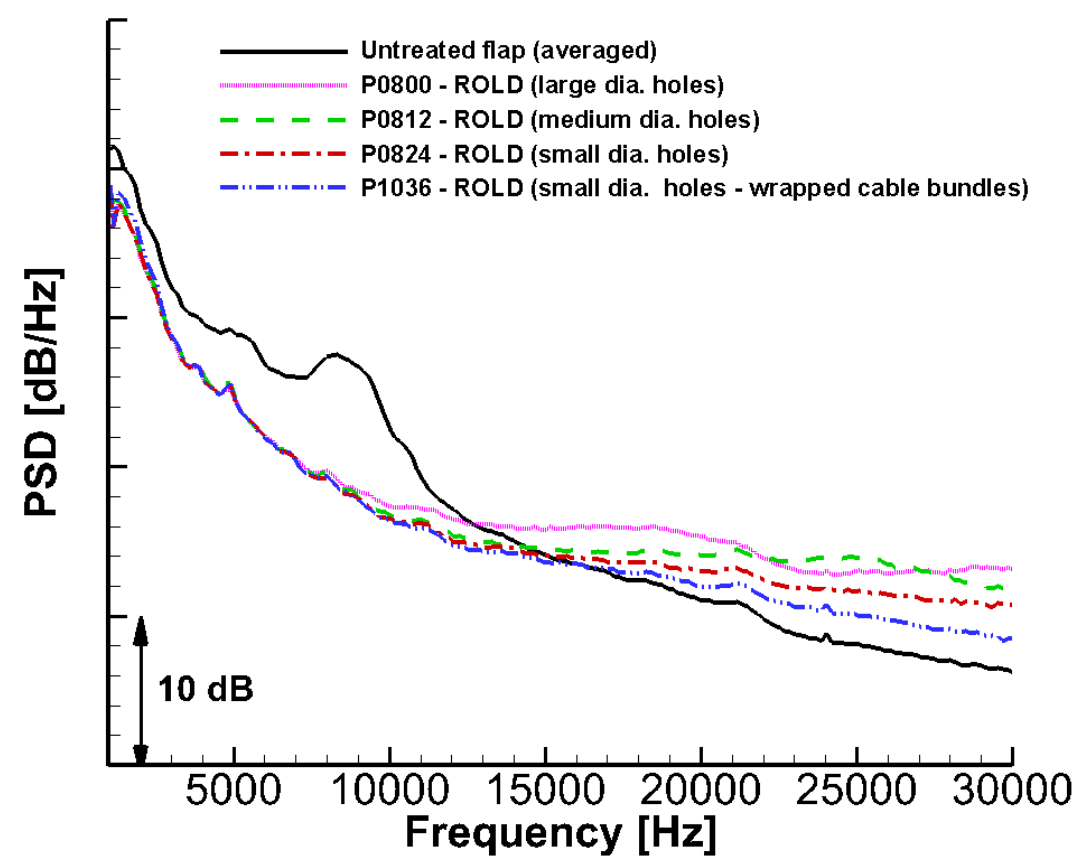

Figure 25. Acoustic performance of ROLD concept.

\section{G. Reduction of Main Landing Gear Noise}

The configuration with a retracted flap $\left(0^{\circ}\right.$ deflection, cruise wing) and the gear installed was used to isolate gear noise and to evaluate the noise reduction concepts. The acoustic behavior of the landing gear fairings described earlier (see Fig. 9) is summarized in Fig. 26. For frequencies above $3 \mathrm{kHz}$, the porous knee fairing (PKF) provided approximately $1.2 \mathrm{~dB}$ of noise reduction. Most of the gain comes from reduced flow interaction between the front and rear posts. Although difficult to discern from the PSD plots, the addition of the upper fairings (UP) to the gear increased the noise reduction benefits by a modest $0.2 \mathrm{~dB}$ at most frequencies. Adding the wheel fairing (WF) to the 
combination of UF and PKF produced a moderate improvement in noise reduction at frequencies between $9-22$ $\mathrm{kHz}$. As is evident in this figure, higher levels of noise abatement were achieved when the wheel fairing was made porous. Although the trend begins at $9 \mathrm{kHz}$, the more substantial benefits were obtained in the $18-30 \mathrm{kHz}$ frequency range, with the amount of reduction increasing with frequency. At frequencies above $20 \mathrm{kHz}$, the porous wheel fairing (PWF) provided nearly $2 \mathrm{~dB}$ more reduction than the non-porous version. Note that the $15-25 \mathrm{kHz}$ range is a significant contributor to the calculation of full-scale PNL values.

The combination of UF and PKF, with either WF or PWF, produced the largest amount of noise reduction from the collection of structures composing the main landing gear. However, none of the gear concepts discussed so far (individually or combined) reduced low-frequency (below $3 \mathrm{kHz}$ ) noise, which is nearly two orders of magnitude higher than that encountered at medium and high frequencies. Thus, the integrated OASPL is dominated by sub 5 $\mathrm{kHz}$ noise. While testing the isolated Goodrich gear during the two wind tunnel entries at Virginia Tech, the low frequency noise was determined to be caused by the wheel well (cavity). Of the several mitigation strategies that were developed and tested, the most effective was placing a stretchable mesh over the cavity interface (opening).

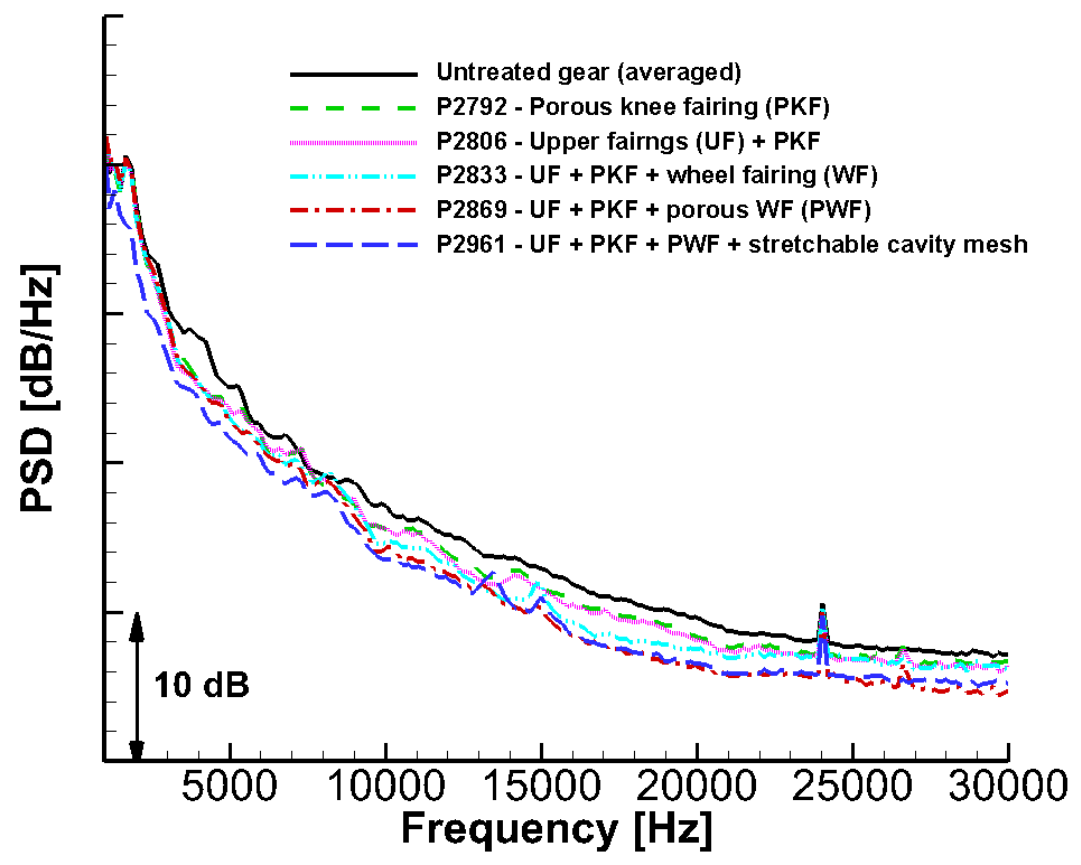

Figure 26. Relative acoustic behavior of main landing gear fairings.

The effectiveness of the stretchable cavity mesh (SCM) in reducing the low frequency component of gear noise is demonstrated in Fig. 26. Addition of the SCM to the other gear fairings (P2961) reduced the noise $2-3 \mathrm{~dB}$ for frequencies lower than $3 \mathrm{kHz}$. The noise reduction benefits obtained with this combination extended to frequencies as high as $9 \mathrm{kHz}$. The synergistic effect of the combined treatments resulted in a reduction of landing gear noise of at least $3 \mathrm{~dB}$. A cautionary comment regarding cavity noise and its mitigation is warranted. Both original and Goodrich main landing gears are close replicas of the full-scale aircraft geometry, with one major difference. In the $18 \%$ scale model, the wheel cavity extends inside the fuselage to a region near the tunnel floor where it was closed off to maintain the model's semi-span considerations. Although there was an opening from the cavity to the rest of the fuselage (to accommodate instrumentation wires and tubes), the cavity volume was finite. In contrast, in the full scale aircraft, the gear cavity on one side of the wing is connected to the cavity on the opposite side through a massive opening in the fuselage. Further investigation is necessary to determine whether the low frequency noise observed in the $18 \%$ scale model measurements has a counterpart in the full-scale aircraft.

\section{H. Reduction of Combined Gear and Flap noise}

The landing configuration of $39^{\circ}$ flap deflection with the main gear installed was used to evaluate the aeroacoustic performance of the noise reduction concepts when both components were deployed. For the evaluation of gear concepts when installation effects (deflected flap) were present, the smaller width porous (270 Rayl) tips were chosen to represent a quiet flap configuration. With the porous tips installed, we repeated the testing sequence 
used for the isolated gear configuration. The results of this process are shown in Fig. 27. Note from the figure that most of the noise reduction was obtained from the flap concept alone even when the gear was left untreated. For frequencies below $18 \mathrm{kHz}$, application of various gear fairings produced very modest levels of noise reduction. At higher frequencies, the full suite of gear concepts provided $1-2 \mathrm{~dB}$ reduction in noise. Note that, as before, the best overall results are obtained when the cavity mesh is added to the combined gear fairings. The reasons why the gear concepts did not perform better will be presented in the following section when gear-flap interaction effects are discussed. Recall from Fig. 14 that, for this aircraft, the flap is the dominant noise source at most frequencies of interest. Thus, flap noise usually masks gear noise, making it very difficult to determine the full extent of benefits gained from the gear concepts.

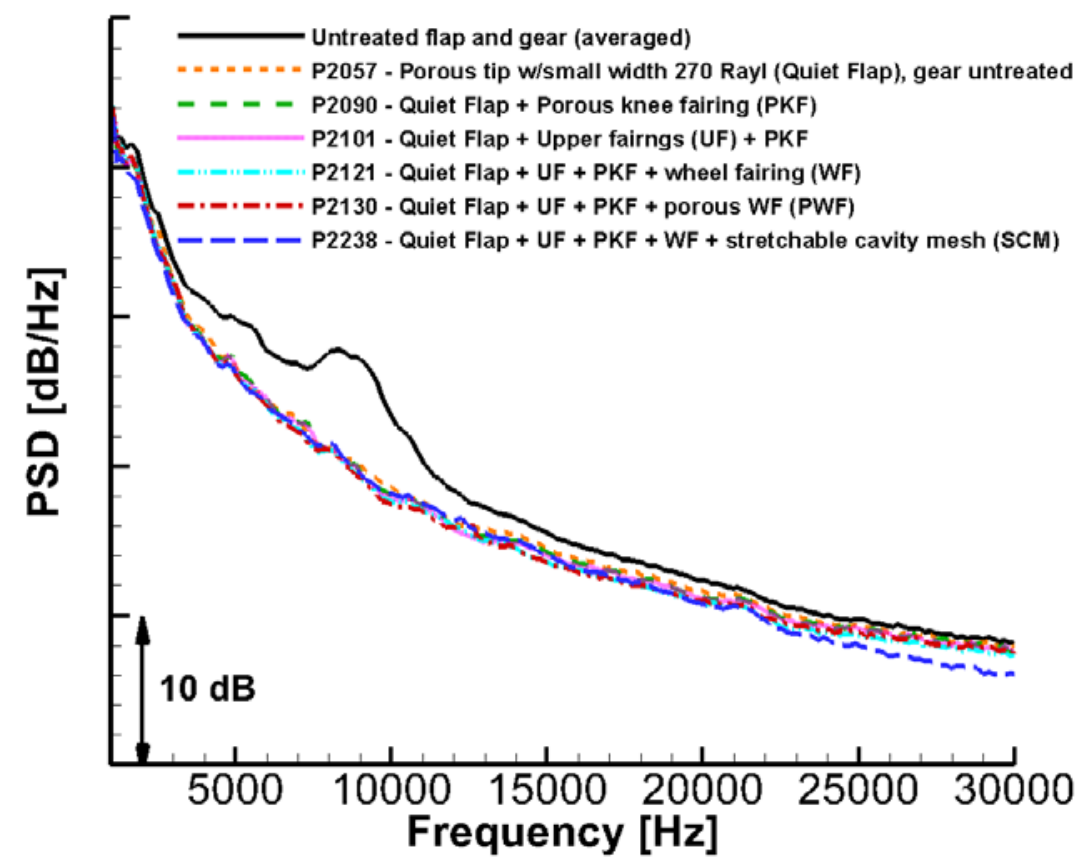

Figure 27. Acoustic performance of main landing gear concepts with quiet flap deflected.

Next, we determined the noise reduction levels attainable by various flap concepts while applying the same suite of gear concepts. Measured PSD spectra for various flap tip treatments are shown in Fig. 28. As expected, because of inherent device noise, the FENoRFins and ROLD concepts provided sub-optimal performance at frequencies greater than $12 \mathrm{kHz}$. Observe from Fig. 28 that all flap concepts produced very similar levels of noise reduction in the $3-10 \mathrm{kHz}$ frequency range. For frequencies above this range, the Nomex liner and the porous tip (nominal width, 570 Rayl) yielded the highest level of noise reduction. At frequencies below $3 \mathrm{kHz}$, the FLEXSEL concept was slightly more effective. 


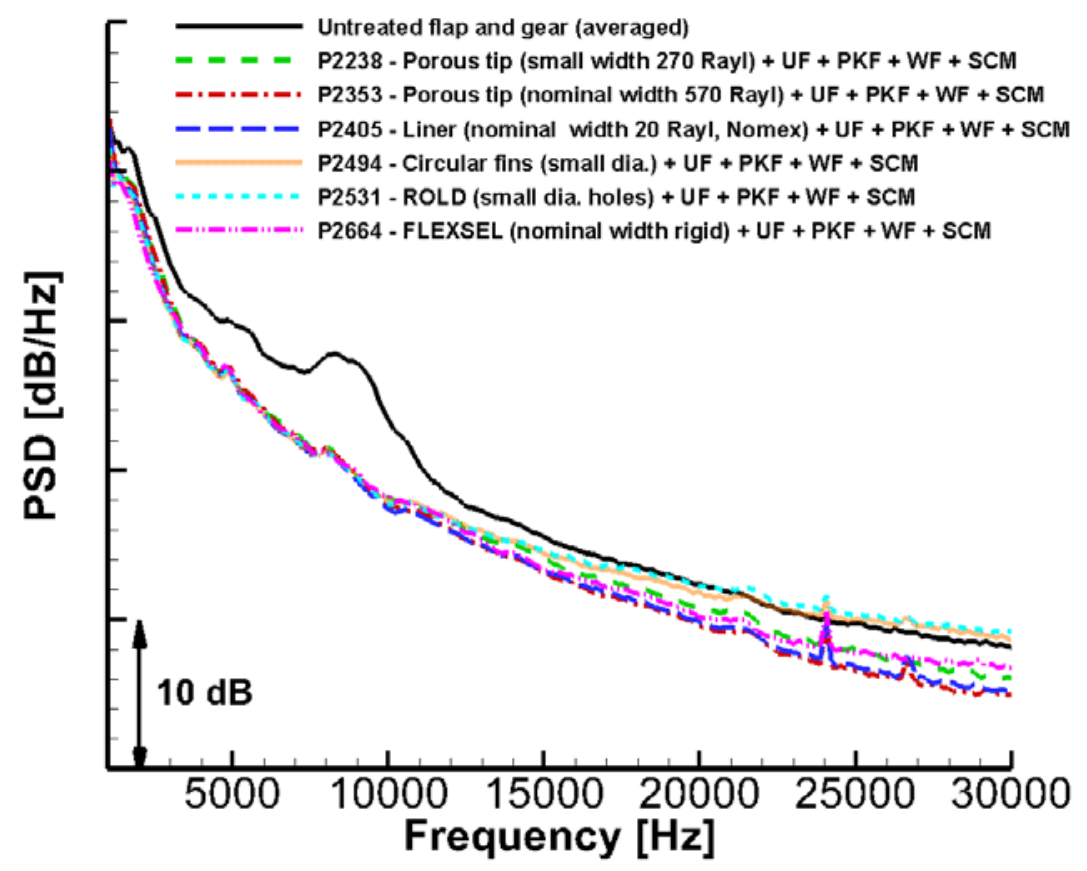

Figure 28. Acoustic performance of flap concepts with quiet main landing gear deployed.

\section{Gear-Flap Interaction Noise}

The noise produced by interactions of the flow past two or more airframe components is one of the most complex and least understood phenomena. For many types of aircraft in use today, the deployed main landing gear is located under the wing and usually aligned with the inboard tip of the deflected flap. As such, the turbulent wake of the main gear typically impinges on the flap side edge at the inboard tip. As shown in Khorrami et al., ${ }^{11,12}$ the resulting surface pressure field (both steady and unsteady) at the flap side edge is different than that encountered when the gear is not deployed. The present test campaign provided an excellent opportunity for a closer examination of gear-flap interaction in a realistic setting and how it may affect farfield acoustic behavior. We present results for the overhead direction $\left(90^{\circ}\right)$ only, since other directivity angles showed similar trends.

Figure 29 presents a comparison of the spectra for the baseline flap (blank tips) with the main gear off, baseline gear with flap retracted to its cruise position ( $0^{\circ}$ deflection), and the landing configuration where both flap and gear are deployed. Also shown in this figure is the spectrum obtained by adding (on a pressure squared basis) the isolated flap and gear spectra. Direct comparison of the noise levels associated with the latter combination and the landing configuration where both components are deployed at the same time is quite informative. Notice that except for a small frequency range of $4-10 \mathrm{kHz}$ (where outboard tip cavity noise is prominent), the combination of the isolated flap and main gear spectra is nearly $40 \%$ higher $(1.5 \mathrm{~dB})$ than the measured noise when they are deployed simultaneously. However, the noise levels associated with the isolated flap (P1013) are relatively close to the levels obtained for the landing configuration (P1862). This trend suggests that there is significant reduction in the radiated sound produced by the main gear when the flap is deflected at $39^{\circ}$. The simplest explanation for this reduction is the lowering of the incoming flow speed (due to the downwash effects of a deflected flap) experienced by the main gear. Assuming a modest decrease of $5 \%$ in the incoming flow speed and a $\mathrm{M}^{6}$ scaling for the gear noise yields a $1.34 \mathrm{~dB}$ reduction in noise levels. The underlying causes for the observed reduction in gear noise (in the presence of the flap) are being investigated using the companion high-fidelity simulations that were recently completed. ${ }^{24,25}$

The baseline spectra of Fig. 29 are repeated in Fig. 30, where PSD values corresponding to one of the quietest gear configurations tested (see Fig. 26) are also included. Notice that the noise levels obtained from combining the isolated baseline flap and quiet gear configurations (P1013+P2961) are only slightly above the levels for the case when both components are deployed at the same time (P1862). This trend provides yet another indication that component interaction brings down the noise levels produced by the gear while the levels associated with the flap remain virtually intact. In general, one may infer that the noise reduction levels from slowing the flow over the untreated gear are nearly the same as the reductions one obtains with the gear concepts installed. To introduce further proof for this hypothesis, corresponding data for a quiet flap are presented in Fig. 31. In this set of plots, untreated and treated isolated main gear results are used to illustrate the point. For the untreated gear, there is a 
noticeable difference between the noise levels of the combined isolated components (P1147+P2749) and the levels when both gear and flap are deployed simultaneously (P2057). When the gear is treated, the combined sound pressure spectrum for the two isolated components (P1147+P2961) is very similar to that when an untreated gear and a quiet flap are deployed simultaneously (P2057). The results shown in Fig. 31 reinforce the conclusion that gear-flap interaction mostly affects gear noise by reducing the magnitude of the radiating sound field considerably. Also evident from this figure is that, for landing configurations when flap noise is dominant, additional reduction of gear noise would be very difficult to measure and quantify.

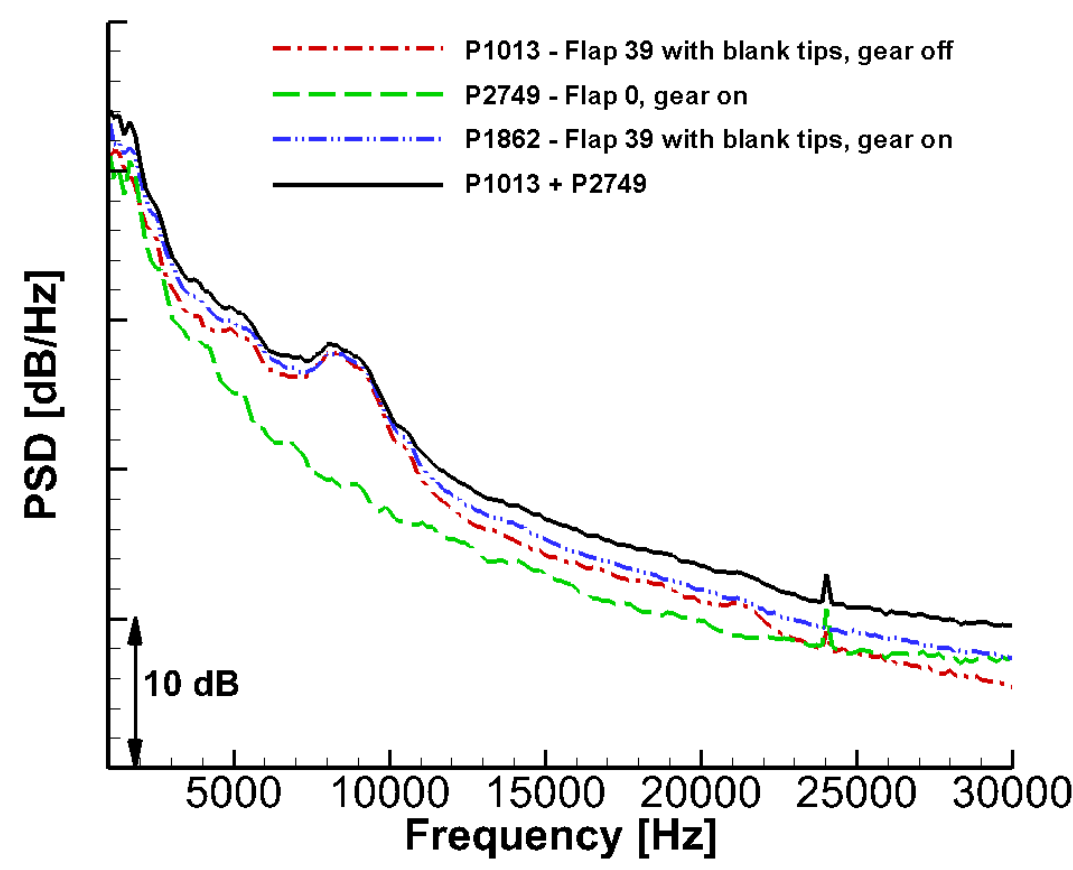

Figure 29. Gear-flap interaction noise for baseline configurations.

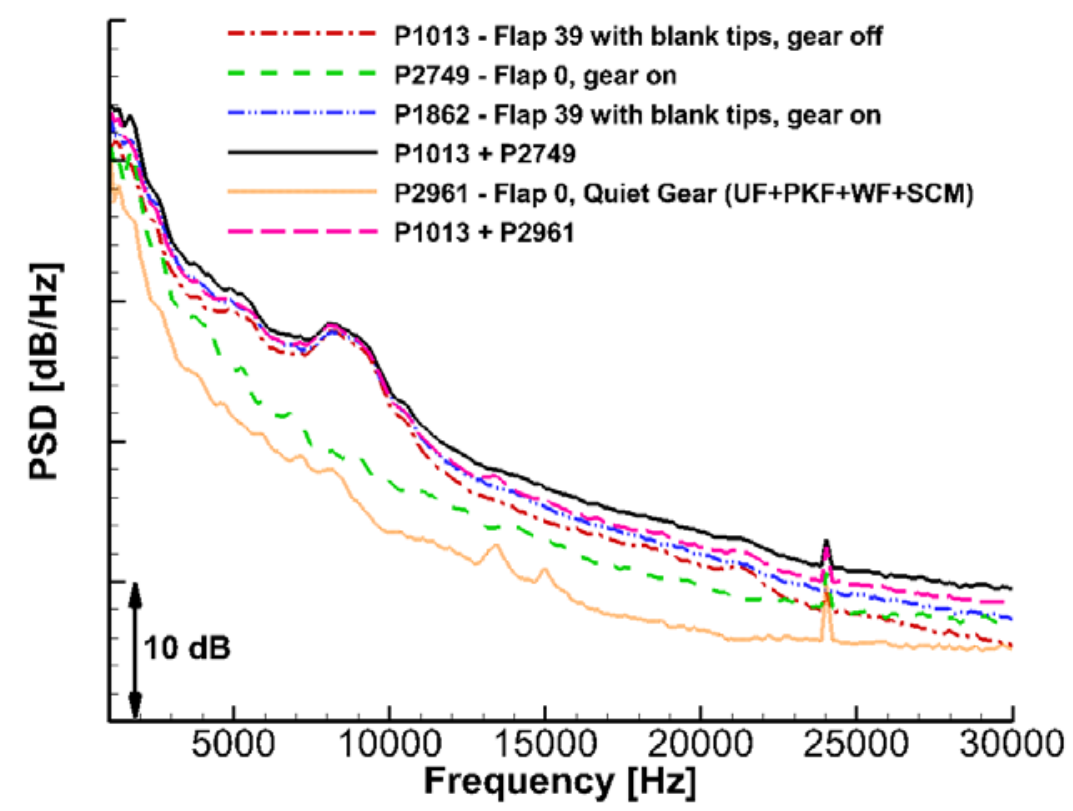

Figure 30. Gear-flap interaction noise for baseline flaps. 


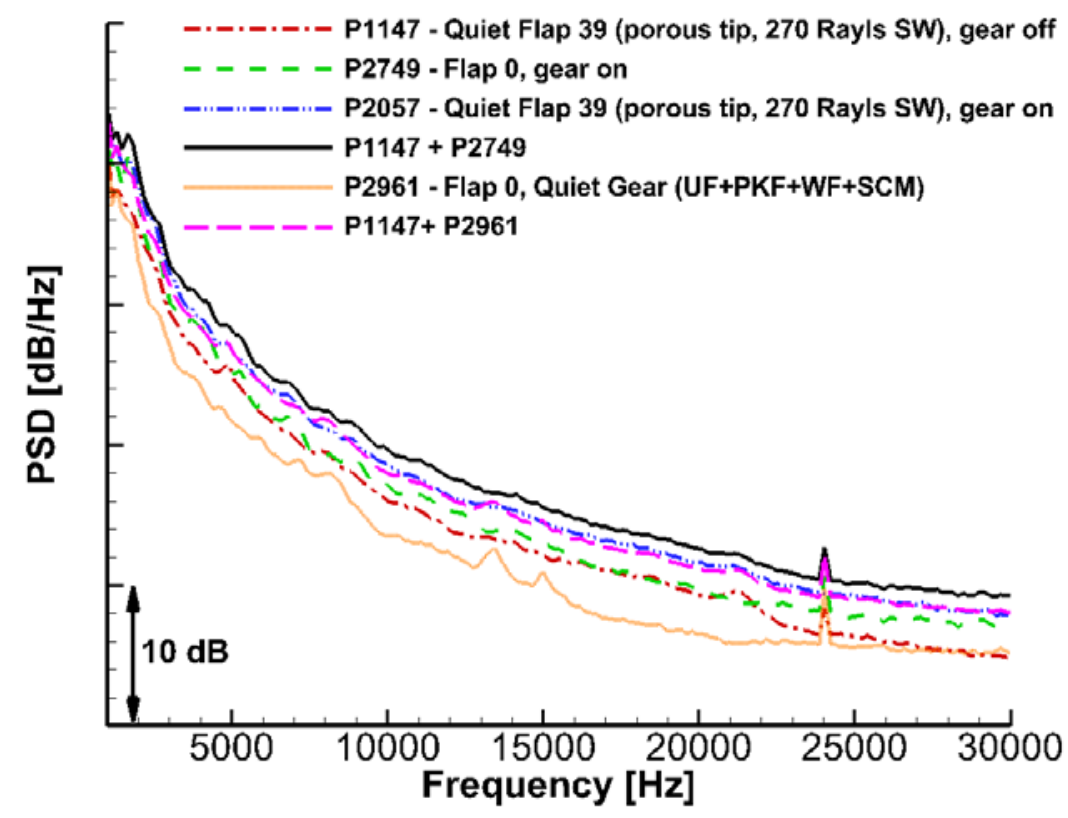

Figure 31. Gear-flap interaction noise for quiet flaps.

\section{Concluding Remarks}

This paper discusses the results of an aeroacoustic test campaign focused on mitigation of airframe noise associated with aircraft flaps and landing gear. Towards achieving that goal, an $18 \%$ scale, semi-span, high-fidelity model of a Gulfstream aircraft was used as a test bed to conduct detailed studies of the flap and main landing gear noise sources and to evaluate the aeroacoustic performance of numerous noise reduction concepts. Acoustic measurements were acquired in the NASA LaRC $14 \times 22$ wind tunnel by using a traversing microphone array in the flyover direction, covering directivity angles between $56^{\circ}$ and $116^{\circ}$. The facility was configured in the acoustically treated open-wall (jet) mode. Most of the data were obtained with the model in a landing configuration with the flap deflected at $39^{\circ}$ and the main landing gear alternately installed and removed. A configuration of $0^{\circ}$ flap deflection (cruise wing) with the main gear deployed was used to determine the effectiveness of isolated gear concepts. Data were collected at Mach numbers of $0.16,0.20$, and 0.24 and angles of attack of $3^{\circ}, 4^{\circ}$, and $5^{\circ}$. Results have only been presented for the overhead $\left(90^{\circ}\right)$ directivity angle with flow conditions of Mach 0.2 and AOA $=3^{\circ}$. This initial examination of the data has revealed the expected trends with parameter variation; a more detailed analysis of the full results to investigate all possible combinations has been initiated.

Tunnel background noise was measured with an empty test section, with and without flow, employing the microphone array positioned at all the flyover directivity angles used to acquire the model acoustic signature. Although not ideal at frequencies lower than $3 \mathrm{kHz}$, the background noise was deemed sufficiently low for proper acquisition of acoustic data associated with airframe noise reduction concepts.

Using the $39^{\circ}$ flap deflection with the main gear removed as a reference configuration, a significant number of low-noise concepts for flaps were evaluated. Most of the concepts tested can be organized into five broad categories: a) porous skin treatment, b) bulk and locally reactive acoustic liners, c) Flap Edge Noise Reduction Fins (FENoRFins) with both circular and non-circular fin cross sections, d) FLEXible Side-Edge Link (FLEXSEL), and e) Reactive Orthotropic Lattice Diffuser (ROLD). During the initial stages of flap concept evaluation, two wiring bundles and the two middle flap brackets were found to be important secondary noise sources that were masking the full extent of the noise reduction benefits. Wrapping the bundles with a thin layer of soft foam reduced bracket noise significantly, allowing a better assessment of acoustic behavior. The majority of the designs showed good acoustic performance, producing $3-4 \mathrm{~dB}$ noise reduction in the low to medium frequency range. The porous skin treatment and the bulk acoustic liner concepts performed best, reducing flap noise between $3-4 \mathrm{~dB}$ across the entire frequency range. The FENoRFins and ROLD concepts increased noise in the high-frequency range due to device noise. Remedies for reducing or making this type of noise irrelevant at full scale were discussed.

As a third reference case, the configuration with $0^{\circ}$ flap deflection (cruise wing) and main gear on was used to determine the noise reduction potential of several landing gear concepts. Only the best performing concepts, downselected from two previous test campaigns in the Virginia Tech tunnel, were evaluated. Unlike flaps, a combination 
of concepts is required to substantially lower gear noise. The porous knee fairing and porous wheel fairing were the most effective concepts for reducing noise from the main posts and the brake system, respectively. Combined, these two fairings produced $2-3 \mathrm{~dB}$ of noise reduction over the mid- and high-frequency ranges of the farfield spectrum. The low frequency component of gear noise was shown to emanate from the wheel cavity. Placement of a stretchable mesh over the cavity opening lowered cavity noise by more than $2-3 \mathrm{~dB}$ for frequencies below $3 \mathrm{kHz}$. The effectiveness of the stretchable mesh concept was shown to extend to the mid-frequency range, providing up to $1 \mathrm{~dB}$ of additional noise reduction.

Gear-flap interaction, as it affects the noise generated by both components, was examined also. We showed that installation effects have a pronounced impact on gear noise, reducing it substantially when a deflected flap is present. The reduction in gear noise was attributed to a slowing of the flow impinging on the gear caused by flap downwash. Using various combinations of low noise gear and flap, it was demonstrated that flap noise is unaffected by the deployed gear.

\section{Acknowledgments}

This work was supported by the Environmentally Responsible Aviation (ERA) project under the Integrated System Research Program (ISRP) of NASA. We would like to thank the staff of the Langley 14 x 22 facility for their outstanding support and execution of a highly productive test entry. Our appreciation goes to Ron Ganis of Goodrich Landing Gear for his contributions to the fabrication and testing of the Goodrich gear in the Virginia Tech tunnel during the 2011 entry and to Goodrich Company for use of their main landing gear model. We would like to express our gratitude to personnel from AVEC Inc. for their superb execution of the 2011 and 2012 test campaigns in the VA Tech Tunnel. We also wish to thank the following NASA LaRC personnel: Michael Jones and Brian Howerton for their support during liner design; Meelan Choudhari for many productive discussions and help with the flap concepts; Travis Turner and James Moore for their contribution to the design and fabrication of the FLEXSEL concept; Scott Bartram for overseeing the fabrication and installation of the phased array panel in the 14 $\mathrm{x}$ 22; William Culliton for providing electronics support in the fabrication of the phased array panel; and Christopher Bahr for development of high efficiency Matlab routines for preprocessing the array data and for assisting with the porting of the UDAMAS code to the K cluster. Thanks are provided to Karl Wiedemann of Analytical Services and Materials, Inc., for his excellent coding of the UDAMAS software. Thanks are also provided to Daniel Stead (AMA, Inc.) and Dennis Kuchta (Jacobs) for their help with array calibration and debugging. Finally, we are greatly indebted to Lawrence Becker of Northrup Grumman Corporation for his steadfast help with the development, maintenance, and operation of the data acquisition system during the tunnel entry.

\section{References}

${ }^{1}$ Michel, U., Barsikow, B., Helbig, J., Hellmig, M., and Schüttpelz, M., "Flyover Noise Measurements on Landing Aircraft with a Microphone Array,” AIAA Paper 98-2336, May 1998.

${ }^{2}$ Piet, J.-F., Elias, G., and Lebigot, P., "Localization of Acoustic Sources from a Landing Aircraft with a Microphone Array," AIAA Paper 99-1811, May 1999.

${ }^{3}$ Michel, U. and Qiao, W., “Directivity of Landing-Gear Noise Based on Flyover Measurements,” AIAA-99-1956, May 1999.

${ }^{4}$ Pott-Pollenske, M., Dobrzynski, W., Buchholz, H., Gehlhar, B., and Walle, F., "Validation of a Semiempirical Airframe Noise Prediction Method through Dedicated A319 Flyover Noise Measurements,” AIAA Paper 2002-2470, May 2002.

${ }^{5}$ Stoker, R., Guo, Y., Streett, C., and Burnside, N., "Airframe Noise Source Locations of a 777 Aircraft in Flight and Comparisons with Past Model Tests,” AIAA Paper 2003-3232, May 2003.

${ }^{6}$ Sijtsma, P. and Stoker, R., "Determination of Absolute Contributions of Aircraft Noise Components Using Fly-Over Array Measurements,” AIAA paper 2004-2958, May 2004.

${ }^{7}$ Piet, J.-F., Davy, R., Elias, G., Siller, H. A., Chow, L. C., Seror, C., and Laporte, F., “Flight Test Investigation of Add-On Treatments to Reduce Aircraft Airframe Noise,” AIAA Paper 2005-3007, May 2005.

${ }^{8}$ Horne, W. C., James, K. D., Arledge, T. K., Soderman, P. T., Burnside, N., and Jaeger, S. M., “Measurements of 26\%-Scale 777 Airframe Noise in the NASA Ames 40- by 80-Foot Wind Tunnel,” AIAA Paper 2005-2810, May 2005.

${ }^{9}$ Elkoby, R., Brusniak, L., Stoker, R., Khorrami, M. R., Abeysinghe, A., and Moe, J.W., "Airframe Noise Results from the QTD II Flight Test Program,” AIAA Paper 2007-3457, May 2007.

${ }^{10}$ Khorrami, M. R., Lockard, D. P., Humphreys, Jr., W. M., Choudhari, M. M., and Van de Ven, T., "Preliminary Analysis of Acoustic Measurements from the NASA-Gulfstream Airframe Noise Flight Test,” AIAA Paper 2008-2814, May 2008.

${ }^{11}$ Khorrami, M. R., Hannon, J. A., Neuhart, D. H., Markowski, G. A., and Van de Ven, T., “Aeroacoustic Studies of a HighFidelity Aircraft Model: Part 1-Steady Aerodynamic Measurements,” AIAA Paper 2012-2233, June 2012. 
${ }^{12}$ Khorrami, M. R. and Neuhart, D. H, “Aeroacoustic Studies of a High-Fidelity Aircraft Model: Part 2- Unsteady Surface Pressures,” AIAA Paper 2012-2234, June 2012.

${ }^{13}$ Neuhart, D. H., Hannon, J. A., and Khorrami, M. R., “Aerodynamic Measurements of a Gulfstream Aircraft Model With and Without Noise Reduction Concepts," paper to be presented at the 20 ${ }^{\text {th }}$ AIAA/CEAS Aeroacoustics Conference, June 2014.

${ }^{14}$ Yao, C.-S., Jenkins, L. N, Bartram, S. M., Harris, J., Khorrami, M. R., and Mace, W. D., "Flow-Field Investigation of GearFlap Interaction on a Gulfstream Aircraft Model,” paper to be presented at the $20^{\text {th }}$ AIAA/CEAS Aeroacoustics Conference, June 2014.

${ }^{15}$ Choudhari, M. and Khorrami, M. R., “Computational Study of Porous Treatment for Altering Flap Side Edge Flow Field,” AIAA Paper 2003-3113, May 2003.

${ }^{16}$ Streett, C. L., Casper, J. H., Lockard, D. P., Khorrami, M. R., Stoker, R. W., Elkoby, R., Wenneman, W. F., and Underbrink, J. R., “Aerodynamic Noise Reduction for High-Lift Devices on a Swept Wing Model,” AIAA Paper 2006-212, January 2006.

${ }^{17}$ Storms, B., Hayes, J., Jaeger, S., and Soderman, P., “Aeroacoustic Study of Flap-Tip Noise Reduction Using Continuous Moldline Technology,” AIAA Paper 2000-1976, June 2000.

${ }^{18}$ Hutcheson, F. V., Brooks, T. F., and Humphreys, Jr, W. M., "Noise Radiation from a Continuous Mold-Line Link Flap Configuration,” AIAA Paper 2008-2966, May 2008.

${ }^{19}$ Humphreys, Jr., W. M., Brooks, T. F., Bahr, C. J., Spalt, T. B., Bartram, S. M., Culliton, W. G., and Becker, L. E., “Development of a Microphone Phased Array Measurement Capability for the Langley 14 by 22 Foot Subsonic Tunnel,” paper to be presented at the 20 ${ }^{\text {th }}$ AIAA/CEAS Aeroacoustics Conference, June 2014.

${ }^{20}$ Brooks, T. F., and Humphreys, Jr., W. M., "Effect of Directional Array Size on the Measurement of Airframe Noise Components,” AIAA Paper 99-1958, May 1999.

${ }^{21}$ Brooks, T. F., and Humphreys, Jr., W. M., “A Deconvolution Approach for the Mapping of Acoustic Sources (DAMAS) Determined from Phased Microphone Arrays,” Journal of Sound and Vibration, Volume 294, pp. 856-879, 2006.

${ }^{22}$ Brooks, T. F., and Humphreys, Jr., W. M., "Extension of DAMAS Phased Array Processing for Spatial Coherence Determination (DAMAS-C),” AIAA Paper 2006-2654, May 2006.

${ }^{23}$ Spalt, T. B., Brooks, T. F., Bahr, C. J., Plassman, G. E., Becker, L. E., and Stead, D. J., “Calibrations of Langley’s 14- by 22-Foot Subsonic Wind Tunnel in Acoustic Configuration,” 20th AIAA/CEAS Aeroacoustics Conference, Atlanta, GA, June, 2014.

${ }^{24}$ Khorrami, M. R. and Mineck, R. E., “Towards Full-Aircraft Airframe Noise Prediction: Detached Eddy Simulations,” Paper to be presented at the $20^{\text {th }}$ AIAA/CEAS Aeroacoustics Conference in Atlanta, Georgia, June 2014

${ }^{25}$ Khorrami, M. R., Fares, E., and Casalino, D., "Towards Full-Aircraft Airframe Noise Prediction: Lattice-Boltzmann Simulations,” Paper to be presented at the $20^{\text {th }}$ AIAA/CEAS Aeroacoustics Conference in Atlanta GA, June 2014. 